\title{
Effect of a modified nano clay and nano graphene on rheology, stability of water-in-oil emulsion, and filtration control ability of oil-based drilling fluids: a comparative experimental approach
}

\author{
Vahid Nooripoor and Abdolnabi Hashemi* \\ Department of Petroleum Engineering, Ahwaz Faculty of Petroleum, Petroleum University of Technology (PUT), 6199171183, \\ Ahwaz, Iran
}

Received: 29 August 2019 / Accepted: 23 April 2020

\begin{abstract}
During the past decade, researchers have used different Nano-Particles (NPs) due to their unique characteristics for improving formulation of Oil-Based Drilling Fluids (OBDFs). This study is the first research that investigates the effect of a Modified Nano Clay (MNC), namely CLOISITE 5 and non-functionalized Nano Graphene (NG) on rheology, electrical/emulsion stability, and filtration control ability, as the main properties of OBDFs. Initially, five concentrations of both NPs $(0.25,0.5,1,1.5$, and $2 \mathrm{wt} \%)$ were added separately into an NP-free OBDF (the base fluid). Then, rheological properties and electrical stability of all prepared fluids were measured at three 90,140 , and $180{ }^{\circ} \mathrm{F}$ temperatures. Moreover, filtration test was carried out under 500 psi $(3447 \mathrm{kPa})$ differential pressure and exposed to $300^{\circ} \mathrm{F}$ temperature for all fluids. Since experimentally measured shear stresses followed well both Herschel Bulkley (shear-thinning) and Bingham Plastic models, effects of temperature and the NPs concentration on both model parameters are investigated more deeply in the paper. Activation energies calculated from Arrhenius model showed that MNC is more effective than NG on reducing the dependency of apparent and plastic viscosities of the base fluid on temperature. MNC, due to its amphiphilic structure, significantly stabilizes water-in-oil emulsion at all temperatures and concentrations, but NG with high electrical conductivity reduces the emulsion stability. The nanofluids containing 0.5 wt\% MNC and $0.25 \mathrm{wt} \% \mathrm{NG}$ which have respectively $32.6 \%$ and $43.5 \%$ fewer filtrate volumes than the base fluid, were considered as the optimal nanofluids from controlling filtration into formation aspect. Finally, MNC is applicable to enhance the formulation of the OBDF through supporting its commercial viscosifier, emulsifiers, and fluid loss control agent, but the negative effect of NG on emulsion stability limits its application.
\end{abstract}

\section{Nomenclature and abbrevations}

$\begin{array}{ll}\text { WBDF } & \text { Water-Based Drilling Fluid } \\ \text { OBDF } & \text { Oil-Based Drilling Fluid } \\ \text { MWCNT } & \text { Multi-Walled Carbon Nano Tube } \\ \text { NG } & \text { Nano Graphene } \\ \text { NP } & \text { Nano Particle } \\ \text { MNC } & \text { Modified Nano Clay } \\ \text { pcf } & \text { Pound per Cubic Feet } \\ \text { RPM } & \text { Round Per Minute } \\ \text { AV } & \text { Apparent Viscosity } \\ \text { PV } & \text { Plastic Viscosity } \\ \text { YP } & \text { Yield Point } \\ \text { GS } & \text { Gel Strength } \\ \theta & \text { Dial Reading } \\ \text { HTA } & \text { Hydrogenated Tallow Alkyl } \\ \text { IFT } & \text { Interfacial Tension }\end{array}$

* Corresponding author: a.hashemi@put.ac.ir

$\begin{array}{ll}\mu \mathrm{A} & \text { micro Ampere } \\ F & \text { Electrical force } \\ V & \text { Electrical Voltage } \\ E & \text { Electrical field } \\ R & \text { Electrical Resistivity } \\ I & \text { Electrical current } \\ 1 \mathrm{bbl}(\mathrm{barrel}) & 0.159 \mathrm{~m}^{3} \\ 1 \mathrm{drum} & 0.220 \mathrm{~m}^{3} \\ 1 \mathrm{sack} & 55(\mathrm{lb}) \mathrm{pound}=24.9425 \mathrm{~kg} \\ 1 \mathrm{lb} / 100 \mathrm{ft}^{2} & 0.478 \mathrm{~N} / \mathrm{m}^{2}(\mathrm{~Pa})=0.937 \mathrm{dial} \mathrm{reading} \\ 1 \mathrm{cp} & 1 \mathrm{mPa} \mathrm{s} \\ 62.4 \mathrm{pcf} & 1 \mathrm{~g} / \mathrm{cm}^{3}\end{array}$

\section{Introduction}

According to industrial developments and population growth, it is necessary to access new oil and gas energy 
sources $[1,2]$. Drilling fluid plays a vital role to drill a safe and effective well [3] to achieve the energy sources. Typical functions of drilling fluid consist of formation pressure control, cutting transport, wellbore stabilization and cooling/ lubricating the bit and drill string $[4,5]$. Drilling fluids are categorized into Oil-Based Drilling Fluids (OBDFs), Water-Based Drilling Fluids (WBDFs), and gaseous fluids [6]. OBDFs are used to drill troublesome shales, pay zone, highly deviated holes, and High Pressure/High Temperature (HPHT) wells. Advantages of OBDFs over WBDFs include high wellbore stability, low torque and drag, appropriate filtration control, suitable rheological properties, and high thermal stability [7]. High cost per barrel and environmental issues of these fluids, which led to the limitation of utilizing them in some countries such as the USA, the United Kingdom, Nigeria, Norway, Saudi Arabia, and Qatar, are considered as OBDFs' disadvantages [8]. But, the noticeable performance of these fluids in shale formations and pay zone motivates researchers to continue their studies on them.

Nanotechnology could be used in different petroleumrelated fields, including exploration, reservoir management, drilling, completion, production, processing, and refinery. Any fluid consisting of at least one additive with particle size less than $100 \mathrm{~nm}$ utilized in the oil and gas industry to explore and exploit oil and gas, is defined as nanofluid [9]. The simplest nanofluid is a two-phase system containing Nano-Particles (NPs) that can move freely through a liquid phase with random Brownian motions [10]. The higher surface area of NPs in comparison to an equal mass of coarser particles enhances their strength and electrical properties as well as makes them more chemically reactive [11-13]. Nowadays, engineers are trying to design drilling fluids that could be stable mechanically, chemically, and thermally [14] to produce oil and gas from complex reservoirs, so NPs can be useful to fulfill their goal.

OBDFs have three main characteristics, including rheological properties, emulsion stability, and filtration control properties. One of the most dominant challenges during drilling HPHT wells using OBDFs is to stabilize rheological properties for reducing the probability of kick, formation damage, and other hazards [15]. Organoclays that are provided after surface modification of clay minerals using organic compounds (i.e., aliphatic ammonium salts [16]), are typical additives for providing rheology for OBDFs [17-24]. There are different studies on the effect of nanosized organoclays on rheological properties of oil-based systems at high pressures and/or high temperatures [19, 21, 25-28], but finding new organoclays as rheology control agent is still attractive for drilling fluid engineers. Besides, since hydrophobic NPs made of carbon element, are thermally high stable, they could be dispersed in OBDFs as rheology provider. There are different efforts for enhancing rheological properties of oil-based systems using various types of carbon element NPs, including Multi-Walled Carbon Nano Tube (MWCNT) [29-31], nano-graphite [32], carbon black [30], nanocomposites of MWCNT and graphene [5] and Nano Graphene (NG) [33], in which rheological behavior of NG-hydrogenated oil suspension has been investigated only at shear rates in the range
$0-140 \mathrm{~s}^{-1}$. The rheological behavior of NG-hydrogenated oil suspension obtained by Ho et al. [33], has been compared to CNT-hydrogenated oil suspension by Chai et al. [34]. Since shear rates in drilling of oil and gas wells are at a higher level, laboratory investigation of NG effect on rheological properties of oil-based systems requires higher shear rates, almost up to $1000 \mathrm{~s}^{-1}$.

OBDFs, due to consisting of a water-in-oil emulsion are known as invert emulsion drilling fluids. Stabilizing the emulsion is a crucial property for these fluids to avoid unfavorable operational problems such as barite sag [6] that can cause operational issues such as stuck pipe and loss circulation [35]. Also, the emulsion stability of OBDF influences on its rheology [36-38], which is effective on the required pumping pressure and the drilling fluid cutting transport ability [36]. Electrical methods are one of the non-destructive methods to evaluate emulsions containing water and oil. When a water-in-oil emulsion is under the effect of an increasing $\mathrm{AC}$ electric field, there is no flow of electrical current up to a critical voltage in which the emulsion breaks down. This critical voltage is a function of the stability of the emulsion, so a high critical voltage is an indicator of a stable emulsion [39, 40]. There is limited literature about NPs' impact on the electrical stability of OBDFs compared to other properties of the fluids. Madkour et al. observed: electrical stability of OBDFs containing $0.5 \mathrm{wt} \%$ polymeric composite of NG and MWCNT equals $750 \mathrm{mv}$, which is the same as the base fluid, so these NPs have no effect on OBDFs' emulsion stability [5]. Growcock et al. concluded: increasing organoclay concentration causes a slight increase in electrical stability of an OBDF with an oil/water ratio of 85/15 containing 4 pounds per barrel of each of the primary and secondary emulsifiers, but bentonite reduces its electrical stability, significantly [41]. Since organoclays' influence on the stability of invert emulsion depends on their clay types and surface modifiers, providing new organoclays to improve OBDFs' electrical stability significantly is economically attractive to reduce the need for commercial emulsifiers.

Filtration control is the third important property of OBDFs. Appropriate filtration control ability is necessary to prevent differential sticking and minimize formation damage [42]. NPs can reduce fluid loss due to their suitable particle size, hydrodynamic characteristics, and high surface area [43]. Madkour et al. also showed: both nanofluids containing polymeric composites of NG and MWCNT have filtrate volumes, respectively, $22 \%$ and $11 \%$ lesser than that of the base fluid [5]. Adding 2-3 vol\% of a lubricant consisting of NG into a WBDF formulation used in one of the onshore wells in Myanmar caused a 30\% reduction in its fluid loss [44]. Adding 1 vol\% MWCNT into an OBDF led to $16.6 \%$ reduction in its HPHT filtration under 500 psi pressure and $280{ }^{\circ} \mathrm{F}$ temperature [29]. Adding $3 \mathrm{wt} \%$ Nano-graphite particles with $40 \mathrm{~nm}$ diameter into an OBDF reduced its API fluid loss by 50\% [32]. Devereux noted that like bentonite clay in WBDFs, organoclays would be effective on filtration properties of OBDFs, but their filtration control ability in OBDFs is difficult at concentrations less than 2 parts per billion [45]. Growcock et al. observed: by increasing organoclay content in an OBDF formulation from 
Table 1. Characterization of the NPs.

\begin{tabular}{lcc}
\hline Nanoparticle & $\begin{array}{c}\text { Nano } \\
\text { graphene }\end{array}$ & $\begin{array}{c}\text { Modified } \\
\text { nano clay }\end{array}$ \\
\hline Size $(\mathrm{nm})$ & $20-30$ & $50-70$ \\
Density $\left(\mathrm{g} / \mathrm{cm}^{3}\right)$ & 0.35 & 1.77 \\
Crystallinity (\%) (XRD) & 53 & 47 \\
Color & Black & Off white \\
Purity (\%) & 98 & Unknown \\
Supplier & United Nanotech Innovation & BYK (a member of $A L T A N A)$ \\
\hline
\end{tabular}
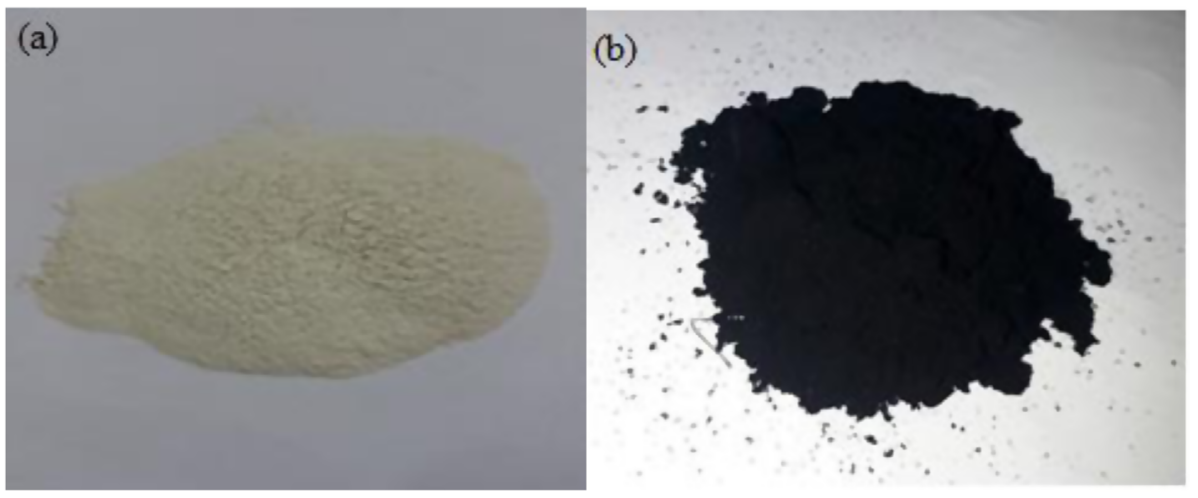

Fig. 1. (a) Modified nano clay, (b) nano graphene.

4 pounds per barrel up to 8 pounds per barrel, HPHT filtration is reduced by $50 \%$ [41]. Nowadays, despite the previous studies about filtration properties of NP-OBDF systems, finding new NPs that can reduce filtration into the formation at low concentrations requires still more effort.

OBDF is the typical drilling fluid for drilling pay zones in many countries, such as Iran. So, improving OBDF's formulation to enhance its characteristics by minimum costs through minimization of materials consumption and improvement of drilling fluid properties has a high degree of importance. Finding multifunction materials can be useful for reducing the total drilling costs. NPs are thermally high stable and have higher surface area compared to traditional materials, so they are potent candidates for improving OBDFs' formulation.

As mentioned before, OBDFs have three major properties, including rheological, emulsion stability and filtration control properties, but the previous studies on the application of organoclays in OBDFs often had focused on their effect on rheological properties and both other properties have been less investigated. Also, according to the authors' findings, there is just one primary research on the effect of NG without any functionalization on rheological properties of oil-based systems and also no literature about NG effect on electrical stability and filtration of OBDFs. This study is the first research that investigates the effect of two commercially available NPs, a Modified Nano Clay (MNC) namely CLOISITE 5 as an organoclay and non-functionalized NG on all important properties of OBDFs including rheological properties, electrical stability and also the NPs' ability to control filtration into HPHT formations. Also, this study
Table 2. Composition of the base fluid per 100 barrel.

\begin{tabular}{lc}
\hline Material & Quantity \\
\hline Diesel oil & 68.7 barrel \\
First emulsifier & 2.8 drum \\
Lime & 24.3 sacks \\
Fluid loss control & 20 sacks \\
Water $+\mathrm{CaCl}_{2}$ & 22.9 barrel \\
Second emulsifier & 0.93 drum \\
Drill gel (viscosifier) & 5 sacks \\
\hline
\end{tabular}

is the first research that has a comparative approach on the effect of an NP of carbon element and a Nano-sized organoclay on a typical OBDF formulation.

\section{Methodology}

\subsection{Materials selection}

The materials which were used as the base fluid composition in this study have been supplied by "Naft Gostar Company" in Ahwaz city. Also, both NPs, MNC, bis (hydrogenated tallow alkyl) dimethyl, salt with bentonite, and NG have been purchased from "Sahand Petroplastic International Company" in Tehran city. The physical properties of the NPs have been listed in Table 1, and NPs have been shown in Figures 1a and 1b. 


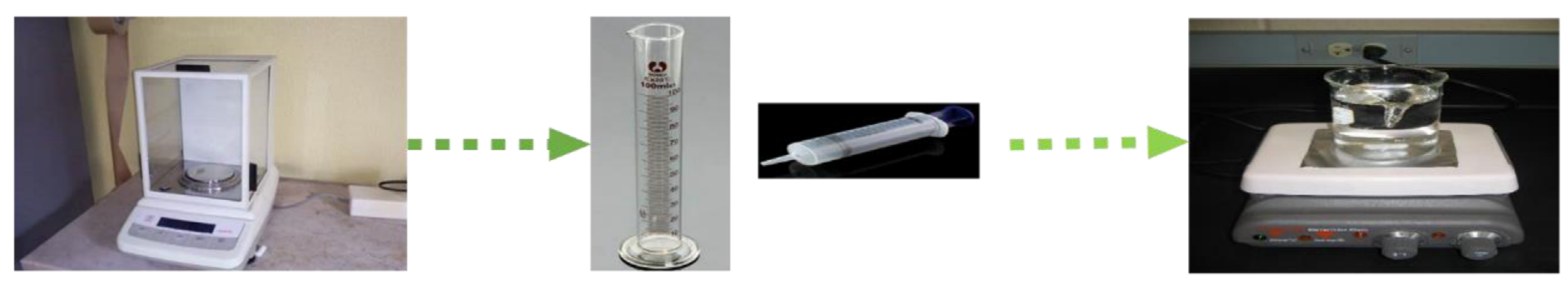

I. Weighting solid additives using lab scale

2. Measuring liquids' volume

3.Preparation of water/calcium chloride solution using hot plate and magnetic stirrer

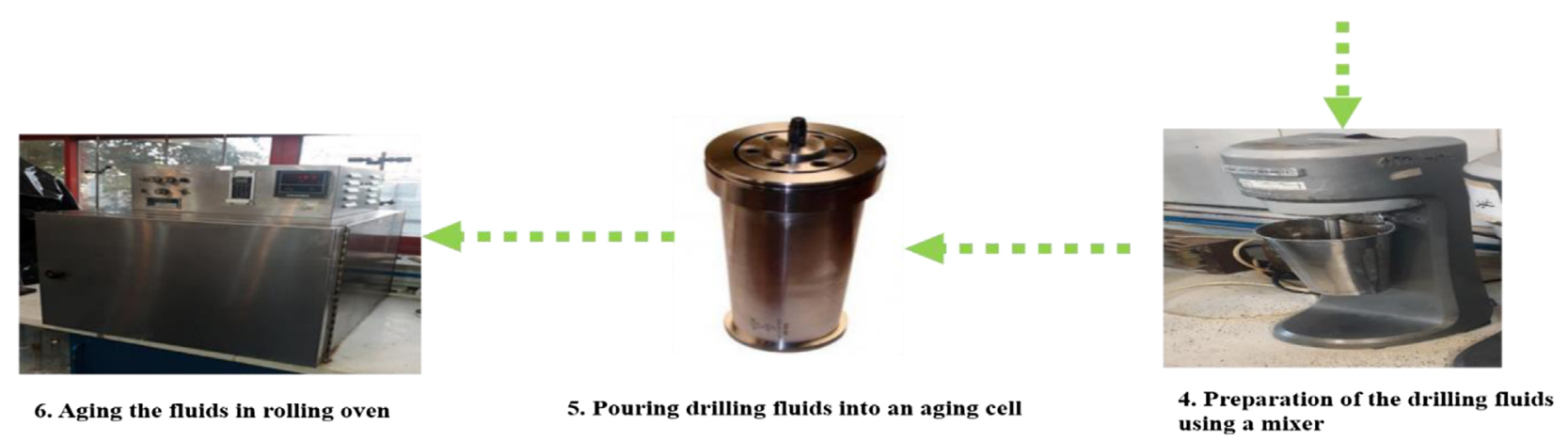

Fig. 2. Procedure of preparing the studied fluids.

\subsection{The base fluid formulation}

Formulation of drilling fluids as complex fluids [46] includes different chemical additives for specific and desirable properties [47]. The composition of the base fluid investigated in this study per 100-barrel drilling fluid has been indicated in Table 2. Oil/water ratio of the base fluid and its density respectively equal to $75 / 25$ and $0.9695 \mathrm{~g} / \mathrm{cm}^{3}$ (60.5 pcf).

\subsection{Fluids preparation}

Figure 2 includes the steps done for preparing the drilling fluids of this study. All fluids were prepared using Hamilton Beach Mixer Model HMD200 at 8500 Round Per Minute (RPM) rotary speed. Then, those samples which must be tested at 140 and $180{ }^{\circ} \mathrm{F}$ temperatures were rolled in OFI testing rolling oven exposed to $200{ }^{\circ} \mathrm{F}$ temperature for $16 \mathrm{~h}$ to determine temperature effect on the drilling fluids when they circulate through pay zone. Arrangement and mixing time of the additives to prepare the samples consisting of $350 \mathrm{~cm}^{3}$ the base fluid (the steps 1-8) is listed as follows:

1. $240 \mathrm{~cm}^{3}$ diesel oil with $0.8493 \mathrm{~g} / \mathrm{cm}^{3}$ density.

2. $13.5 \mathrm{~cm}^{3}$ first emulsifier $/ 10 \mathrm{~min}$.

3. $13.4 \mathrm{~g}$ lime/10 $\mathrm{min}$.

4. $11 \mathrm{~g}$ fluid loss control/15 min.

5. $80 \mathrm{~cm}^{3}$ water + calcium chloride with $1.3141 \mathrm{~g} / \mathrm{cm}^{3}$ density/20 min.

6. $4.5 \mathrm{~cm}^{3}$ second emulsifier $/ 15 \mathrm{~min}$.

7. $2.75 \mathrm{~g}$ drill gel/15 min.

8. If needed, NPs in the required concentration $(0.25,0.5,1,1.5$, and $2 \mathrm{wt} \%) / 15 \mathrm{~min}$.

It must be noted that to prepare a solution of watercalcium chloride with $1.3141 \mathrm{~g} / \mathrm{cm}^{3}$ density, $180 \mathrm{~g}$ calcium chloride has been dissolved into $350 \mathrm{~cm}^{3}$ distilled water. Along the article, each nanofluid is named as "NP concentration and type-OBDF". For example, 1\% NG-OBDF is the nanofluid prepared by the addition of $1 \mathrm{wt} \% \mathrm{NG}$ into the base fluid (NP-free fluid).

\subsection{Rheological properties}

Fann VG Meter Model 35 (the commonest apparatus for rheology tests in oil fields across the world) was used during the rheological measurements based on API Recommended Practice 13B-2 for field testing OBDFs. Since temperature is the most effective parameter on rheological properties, especially viscosity [48], rheological properties of the drilling fluids were measured at three temperatures 90, 140 and $180{ }^{\circ} \mathrm{F}$. Dial readings at six shear rates corresponding to $3,6,100,200,300$ and 600 RPM were measured to determine rheological behavior of the drilling fluids among the three commonest rheological behavior models for drilling fluids, including Bingham Plastic, Power-law, and Herschel Bulkley presented respectively in equations (1)-(3):

$$
\begin{gathered}
\tau=\tau_{0}+\mu_{\mathrm{p}} \dot{\gamma}, \\
\tau=k \dot{\gamma}^{n}, \\
\tau=\tau_{0}+k \dot{\gamma}^{n} .
\end{gathered}
$$

$\tau$ is the shear stress in $\mathrm{Pa}, \dot{\gamma}$ is the shear rate in $\mathrm{s}^{-1}, \tau_{0}$ is the threshold stress in $\mathrm{Pa}, \mu_{\mathrm{p}}$ is the plastic viscosity in $\mathrm{Pa} \mathrm{s}, k$ is the consistency index in $\mathrm{Pa} \mathrm{s}^{n}$ and $n$ is the flow behavior index (dimensionless).

According to API RP 13B-2, experimental values of apparent viscosity, plastic viscosity and yield point that are respectively named $\mathrm{AV}, \mathrm{PV}$, and $\mathrm{YP}$ as the classical rheological properties of Bingham Plastic fluids, were 
calculated using equations (4)-(6), respectively. Also, initial and final gel strengths (GS) in $\mathrm{lb} / 100 \mathrm{ft}^{2}$ correspond to the maximum dial reading at a rotation speed of $3 \mathrm{RPM}\left(\theta_{3 \max }\right)$ respectively measured after $10 \mathrm{~s}$ and $10 \mathrm{~min}$ :

$$
\begin{gathered}
\mathrm{AV}=\frac{\theta_{600}}{2}, \\
\mathrm{PV}=\theta_{600}-\theta_{300}, \\
\mathrm{YP}=\theta_{300}-\mathrm{PV} .
\end{gathered}
$$

$\theta_{600}$ and $\theta_{300}$ are dial readings at 600 and 300 RPM respectively, AV and PV are apparent viscosity, and plastic viscosity in cp and YP is yield point in $\mathrm{lb} / 100 \mathrm{ft}^{2}$. These data are in field unit system, and to convert them into SI system, the following conversion factors must be considered: (1) shear stress in $\mathrm{Pa}=0.51 \times$ dial reading, $(2)$ shear rate in $\mathrm{s}^{-1}=1.703 \times \mathrm{RPM}$, (3) $\mathrm{AV}$ and $\mathrm{PV}$ in $\mathrm{mPa} \mathrm{s}=\mathrm{AV}$ and $\mathrm{PV}$ in $\mathrm{cp}$, (4) $\mathrm{YP}$ or GS in $\mathrm{Pa}=0.478 \times \mathrm{YP}$ or GS in $\mathrm{lb} / 100 \mathrm{ft}^{2}$. Because of the high dependency of rheological properties on shear history and temperature, three separated samples of each drilling fluid at each temperature were tested to reduce the errors as much as possible. Accordingly, all dial readings which will be used in the Results section are the average values after rounding to the nearest quantity measurable by the viscometer. It must be mentioned that the maximum acceptable temperature variation during all measurements is $\pm 5^{\circ} \mathrm{F}$, so final GS of the studied fluids will be reported only at $90^{\circ} \mathrm{F}$.

\subsection{Electrical stability}

To investigate the stability of water-in-oil emulsion in the studied drilling fluids, electrical stability test was performed for all them at three temperatures 90,140 , and $180^{\circ} \mathrm{F}$ using OFI emulsion stability tester according to API Recommended Practice 13B-2 for field testing OBDFs; the confident electrical stability is the average of two measurements.

\subsection{High Pressure/High Temperature (HPHT) filtration}

OBDF often is used as drilling fluid in pay zones. In the pay zone, the pressure and temperature are high, so it is needed to carry out HPHT filtration as a static test to predict filtration in pay zones. In this study, OFI filtration tester was used to measure HPHT filtration of the fluids under $500 \mathrm{psi}(3447 \mathrm{kPa})$ differential pressure and exposed to $300{ }^{\circ} \mathrm{F}$ temperature according to API Recommended Practice 13B-2 for field testing OBDFs. The authors performed three HPHT filtration tests for each drilling fluid with $\pm 0.1 \mathrm{~cm}^{3}$ accuracy.

\section{Results and discussion}

\subsection{Rheological behavior}

Success of drilling operations, especially cuttings removal, depends on the viscous behavior of the drilling fluid [49].
High shear rates applied on drilling fluid using VG Meter in the laboratory are similar to that at bit nozzles during the drilling operation, so it is necessary for drilling fluid to have a less viscosity at high shear rates to can cross through the bit nozzles. At low laboratory shear rates, which are the simulation of the annulus alongside drill pipe and drill collar, a more viscosity is required for carrying drilling cuttings. In a sentence, high drilling fluid viscosity at low shear rates is necessary for keeping cuttings in the suspension, and low viscosity at high shear rates is useful to control drilling fluid pumping costs [6]. Drilling fluids should follow this behavior, which is called shear thinning [50].

Figures $3 \mathrm{a}-3 \mathrm{c}$ and Figures $4 \mathrm{a}-4 \mathrm{c}$ respectively show shear stress versus shear rate for the MNC-OBDFs and NG-OBDFs over the base fluid at the three temperatures 90, 140, and $180^{\circ} \mathrm{F}$. Both NPs lead to increasing shear stress of the base fluid at all temperatures. The shear stress of MNC-OBDFs is more than that of the NG-OBDFs at equal concentrations and shear rates and exposed to the three temperatures 90,140 , and $180^{\circ} \mathrm{F}$. Table 3 indicates the best fitted rheological parameters correspond to Bingham Plastic, Power-law, and Herschel Bulkley models as functions of temperature, NP type, and NP concentration. As the $R$-squared values indicated in Table 3 show, all drilling fluids follow more accurately Herschel-Bulkley rheological behavior model with shear-thinning properties ( $n$ less than unity) at all temperatures. The shear-thinning behavior of the MNC-OBDFs is consistent with the previous studies on the rheological behavior of organoclay suspensions (i.e., PM199 and HDTMA-MMT [24] and B128 [49]). However, the shear-thinning behavior of the NG-OBDFs as an appropriate and positive finding is unlike the shear-thickening behavior of the NG-hydrogenated oil suspensions at shear rates up to $140 \mathrm{~s}^{-1}$ which was reported by Ho et al. [33]. Considering the fitted $n$ values, $2 \%$ MNC-OBDF is thinner than $2 \%$ NG-OBDF at the three temperatures. Overall, it is difficult to interpret the combined effect of temperature and the both NPs concentration on Herschel Bulkley model parameters, especially for NG-OBDFs. As can be concluded from the average flow behavior indexes of $0.7978,0.7657$, and 0.6314 for the MNC-OBDFs, respectively, at 90, 140, and $180^{\circ} \mathrm{F}, \mathrm{MNC}-\mathrm{OBDF}$ s overall are thicker at lower temperatures. So, from the technical point of view, higher pumping power is required to circulate MNC-OBDFs at lower temperatures.

Close average $R$-squared values of 0.9974 for Herschel Bulkley model, 0.9806 for Bingham Plastic model, and 0.9608 for Power-law model, which have been calculated using Regression coefficients of all drilling fluids at all temperatures, show that the experimentally measured shear stresses actually can be well fitted on all three models. Since the accuracy of Bingham Plastic flow behavior model is only $1.68 \%$ fewer than Herschel Bulkley model as well as it is more sensible than Herschel Bulkley model for petroleum engineers because of the simplicity in the calculation of its two parameters, this research will focus on the interpretation of experimentally calculated parameters of Bingham Plastic model. 

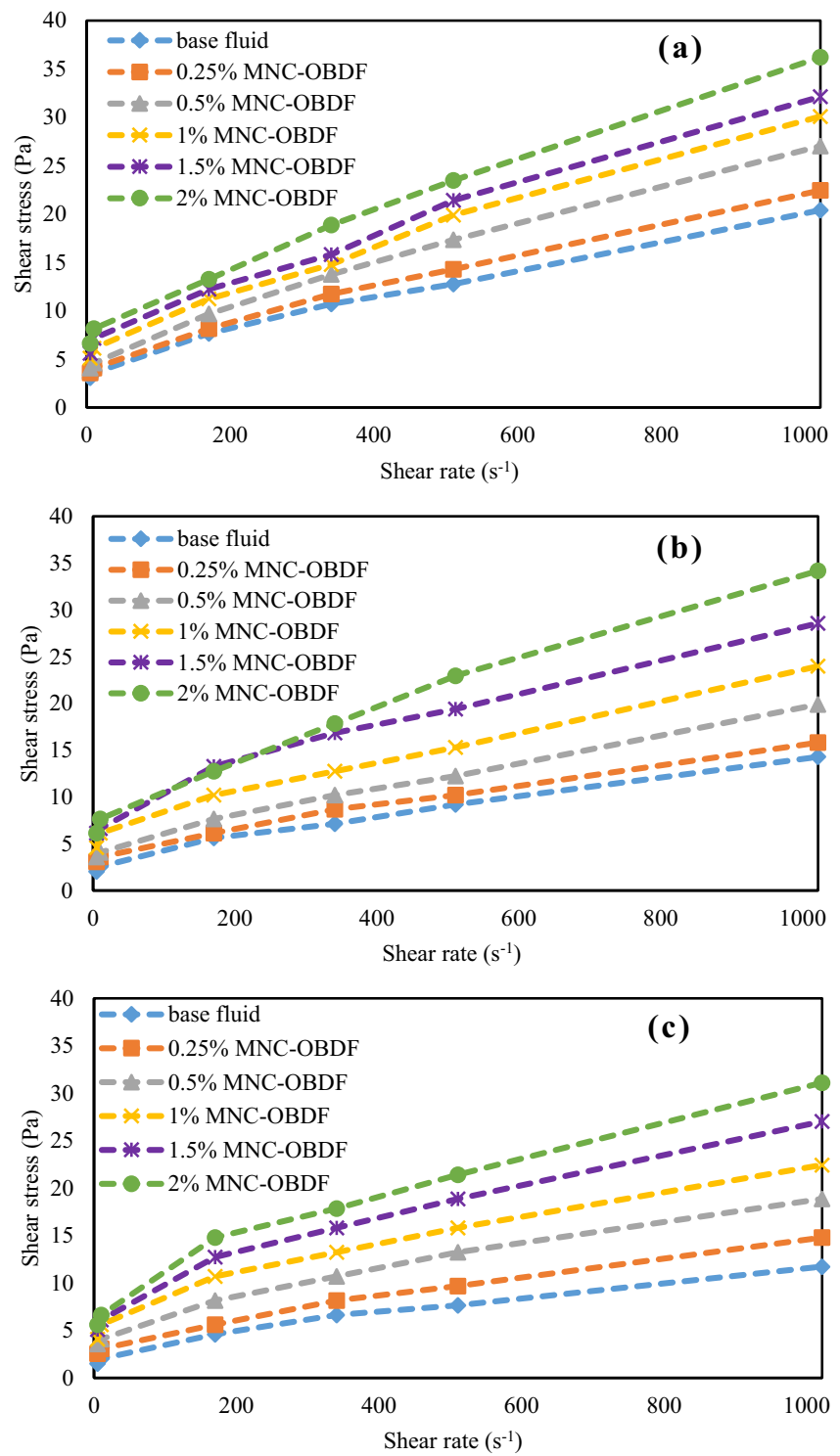

Fig. 3. Rheological behavior of MNC-OBDFs over the base fluid at (a) $90^{\circ} \mathrm{F}$, (b) $140{ }^{\circ} \mathrm{F}$, and (c) $180^{\circ} \mathrm{F}$.

\subsection{Apparent viscosity}

Apparent Viscosity (AV) corresponds to the $\tau / \dot{\gamma}$ ratio at each point for a non-Newtonian fluid. It is a pointwise measurement, which means that it cannot provide information about drilling fluid undesirability. AV reflects the ability of drilling fluids to flow and is effective on the rate of penetration [51]. NPs' effect on AV has been evaluated in previous studies. For instance, drilling fluids containing $0.25-1 \mathrm{gr}$ MWCNT, due to the interaction of NPs-liquid molecules have greater AVs than the NP-free drilling fluid at the temperatures in the range $30-70{ }^{\circ} \mathrm{C}[52]$.

All AV values measured in this study correspond to a $1021.8 \mathrm{~s}^{-1}$ shear rate (600 RPM rotary speed). As shown in Figure 5, both NPs increase the base AV at the three temperatures. Moreover, MNC-OBDFs are more viscous than NG-OBDFs; for example, AV of $2 \%$ MNC-OBDF at
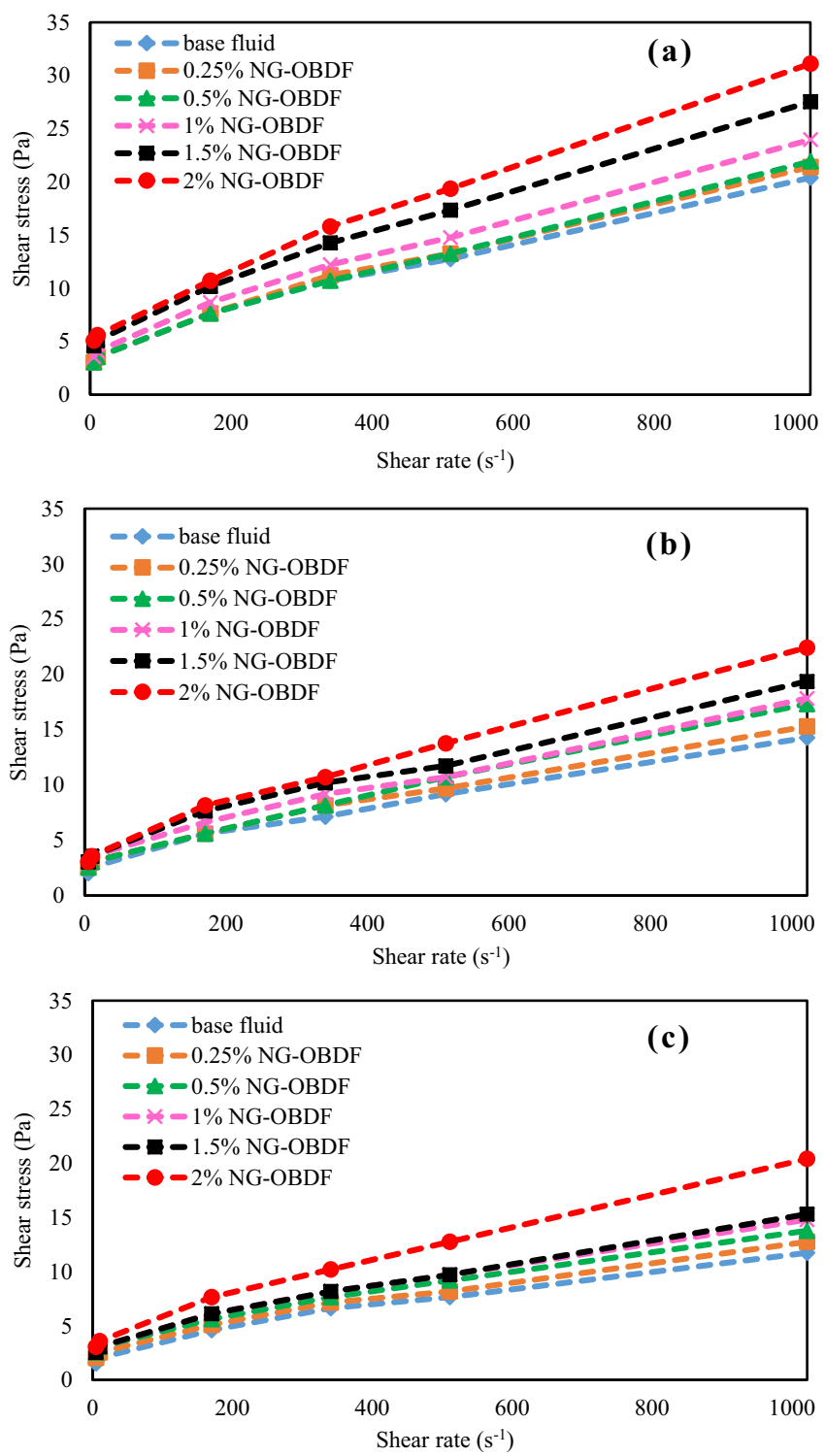

Fig. 4. Rheological behavior of NG-OBDFs over the base fluid at (a) $90^{\circ} \mathrm{F}$, (b) $140{ }^{\circ} \mathrm{F}$, and (c) $180^{\circ} \mathrm{F}$.

90,140 , and $180{ }^{\circ} \mathrm{F}$ is $35.5,33.5$, and $30.5 \mathrm{mPa}$ s, respectively, and AV of $2 \%$ NG-OBDF equals to $30.5,22$, and $20 \mathrm{mPa} \mathrm{s}$ at the three temperatures.

Temperature dependency of the viscosity of the studied fluids is investigated according to Arrhenius model shown in equation (7), which overall is applicable for flow properties of drilling and completion fluids [53]. The model is another form of Andrade equation:

$$
\mu=\mu_{0} \exp \left(\frac{E_{\mathrm{a}}}{R T}\right)
$$

where $\mu$ is the fluid viscosity in $\mathrm{mPa} \mathrm{s}, \mu_{0}$ is a constant value in $\mathrm{mPa} \mathrm{s}, E_{\mathrm{a}}$ is the activation energy for the drilling fluid in $\mathrm{J} / \mathrm{mol}, R$ is the general constant of gases equals to $8.314 \mathrm{~J} / \mathrm{mol}{ }^{\circ} \mathrm{K}$ and $T$ is the absolute temperature in ${ }^{\circ} \mathrm{K}$. The higher activation energy indicates the high dependency of viscosity on temperature [54]. 
Table 3. Comparison of the modeled rheological parameters.

\begin{tabular}{|c|c|c|c|c|c|c|c|c|c|c|c|c|c|}
\hline & & & $\begin{array}{l}\text { Base } \\
\text { fluid }\end{array}$ & $\begin{array}{l}0.25 \% \\
\text { MNC- } \\
\text { OBDF }\end{array}$ & $\begin{array}{l}0.5 \% \\
\text { MNC- } \\
\text { OBDF }\end{array}$ & $\begin{array}{c}1 \% \\
\text { MNC- } \\
\text { OBDF }\end{array}$ & $\begin{array}{l}1.5 \% \\
\text { MNC- } \\
\text { OBDF }\end{array}$ & $\begin{array}{c}2 \% \\
\text { MNC- } \\
\text { OBDF }\end{array}$ & $\begin{array}{c}0.25 \% \\
\mathrm{NG}^{-} \\
\text {OBDF }\end{array}$ & $\begin{array}{c}0.5 \% \\
\text { NG- } \\
\text { OBDF }\end{array}$ & $\begin{array}{c}1 \% \\
\text { NG- } \\
\text { OBDF }\end{array}$ & $\begin{array}{c}1.5 \% \\
\text { NG- } \\
\text { OBDF }\end{array}$ & $\begin{array}{c}2 \% \mathrm{NG}^{-} \\
\mathrm{OBDF}\end{array}$ \\
\hline \multirow{7}{*}{$\begin{array}{l}\text { Bingham } \\
\text { Plastic } \\
\text { model }\end{array}$} & \multirow{2}{*}{$90^{\circ} \mathrm{F}$} & $\mathrm{YP}$ & 3.9637 & 4.4262 & 5.0744 & 6.2212 & 6.9728 & 7.9781 & 3.9454 & 3.7851 & 4.4589 & 5.5389 & 5.9085 \\
\hline & & $R^{2}$ & 0.9830 & 0.9864 & 0.9866 & 0.9887 & 0.9879 & 0.9910 & 0.9843 & 0.9912 & 0.9875 & 0.9882 & 0.9922 \\
\hline & \multirow[t]{2}{*}{$140{ }^{\circ} \mathrm{F}$} & $\mathrm{PV}$ & 0.0117 & 0.0123 & 0.0156 & 0.0181 & 0.0215 & 0.0271 & 0.0123 & 0.0144 & 0.0141 & 0.0155 & 0.0187 \\
\hline & & $R^{2}$ & 0.9808 & 0.9866 & 0.9906 & 0.9834 & 0.9635 & 0.9865 & 0.9866 & 0.9959 & 0.9906 & 0.9810 & 0.9889 \\
\hline & \multirow[t]{3}{*}{$180^{\circ} \mathrm{F}$} & PV & 0.0097 & 0.0118 & 0.0148 & 0.0171 & 0.0208 & 0.0242 & 0.0102 & 0.0108 & 0.0117 & 0.0122 & 0.0167 \\
\hline & & YP & 2.3557 & 3.2536 & 4.6869 & 6.1026 & 7.1266 & 7.9297 & 2.7910 & 3.2719 & 3.3793 & 3.3046 & 3.8781 \\
\hline & & $R^{2}$ & 0.9641 & 0.9809 & 0.9659 & 0.9489 & 0.9529 & 0.9512 & 0.9736 & 0.9786 & 0.9753 & 0.9814 & 0.9871 \\
\hline \multirow{6}{*}{$\begin{array}{l}\text { Power law } \\
\text { model }\end{array}$} & \multirow[t]{3}{*}{$140^{\circ} \mathrm{F}$} & $k$ & 1.1227 & 1.8049 & 2.0379 & 2.9635 & 3.5966 & 3.6362 & 1.4434 & 1.3755 & 1.7390 & 1.6871 & 1.5884 \\
\hline & & $n$ & 0.3389 & 0.2813 & 0.2940 & 0.2702 & 0.2758 & 0.2917 & 0.3089 & 0.3272 & 0.3002 & 0.3217 & 0.3496 \\
\hline & & $R^{2}$ & 0.9735 & 0.9449 & 0.9483 & 0.9480 & 0.9724 & 0.9413 & 0.9532 & 0.9369 & 0.9472 & 0.9685 & 0.9665 \\
\hline & \multirow[t]{3}{*}{$180^{\circ} \mathrm{F}$} & $k$ & 0.8381 & 1.4568 & 2.0491 & 2.6026 & 3.0331 & 3.2579 & 1.1686 & 1.5025 & 1.4667 & 1.4531 & 1.6444 \\
\hline & & $n$ & 0.3600 & 0.3057 & 0.2979 & 0.2926 & 0.2963 & 0.3064 & 0.3188 & 0.2923 & 0.3073 & 0.3105 & 0.3320 \\
\hline & & $R^{2}$ & 0.9847 & 0.9581 & 0.9732 & 0.9813 & 0.9844 & 0.9861 & 0.9731 & 0.9623 & 0.9719 & 0.9671 & 0.9652 \\
\hline \multirow{6}{*}{$\begin{array}{l}\text { Herschel } \\
\text { Bulkley } \\
\text { model }\end{array}$} & \multirow[t]{3}{*}{$90^{\circ} \mathrm{F}$} & $k$ & 0.09463 & 0.09031 & 0.11160 & 0.09305 & 0.09272 & 0.09727 & 0.09295 & 0.06302 & 0.08811 & 0.09851 & 0.08543 \\
\hline & & $n$ & 0.7520 & 0.7718 & 0.7702 & 0.8074 & 0.8152 & 0.8243 & 0.7632 & 0.8221 & 0.7857 & 0.7871 & 0.8262 \\
\hline & & $\tau_{0}$ & 2.923 & 3.400 & 3.809 & 5.122 & 5.873 & 6.820 & 2.904 & 3.036 & 3.440 & 4.397 & 4.891 \\
\hline & \multirow{3}{*}{$180^{\circ} \mathrm{F}$} & $n$ & 0.6474 & 0.7383 & 0.6491 & 0.5841 & 0.5939 & 0.5916 & 0.7003 & 0.7190 & 0.7007 & 0.7456 & 0.7828 \\
\hline & & $\tau_{0}$ & 1.360 & 2.461 & 3.178 & 3.818 & 4.457 & 4.804 & 1.969 & 2.477 & 2.438 & 2.521 & 3.001 \\
\hline & & $R^{2}$ & 0.9975 & 0.9986 & 0.9996 & 0.9957 & 0.9977 & 0.9960 & 0.9966 & 0.9990 & 0.9982 & 0.9973 & 0.9974 \\
\hline
\end{tabular}

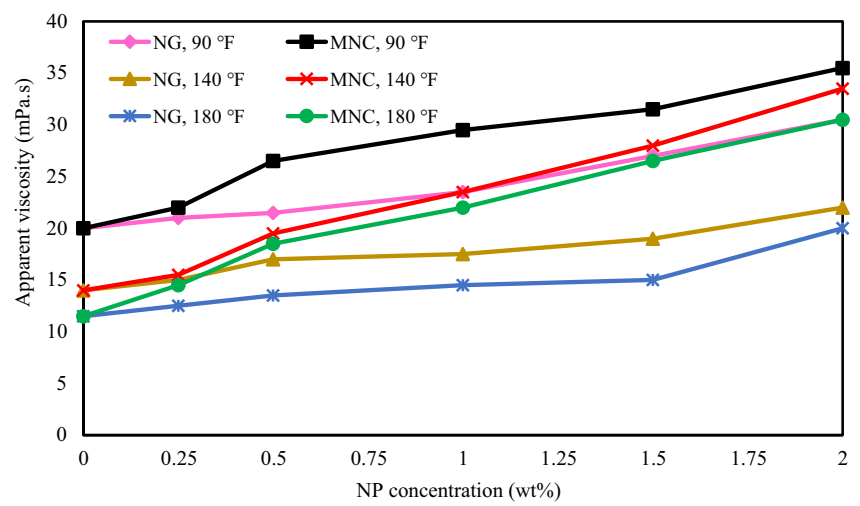

Fig. 5. Apparent viscosity as a function of temperature and NP concentration.

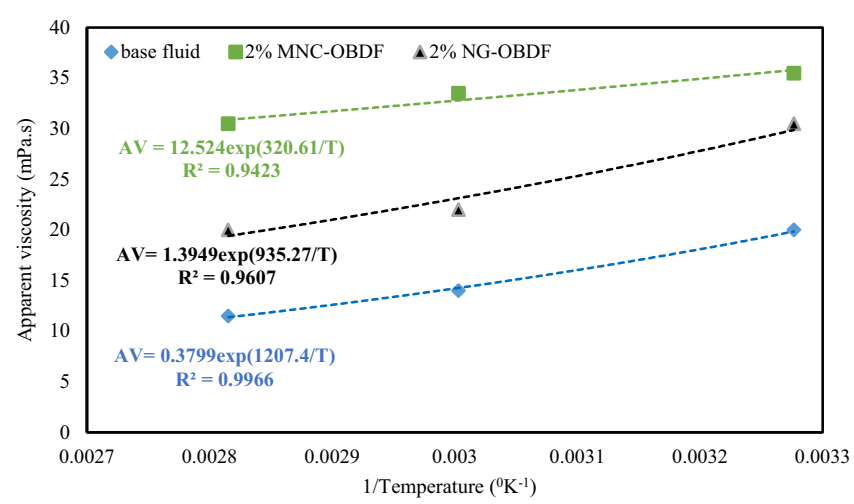

Fig. 6. Arrhenius plot related to $\mathrm{AV}$ for the base fluid, $2 \%$ $\mathrm{MNC}-\mathrm{OBDF}$, and $2 \%$ NG-OBDF. 
Table 4. Arrhenius parameters and Regression coefficients related to AV and PV of all drilling fluids.

\begin{tabular}{lccccccr}
\hline & \multicolumn{3}{c}{$\mathrm{AV}$} & & \multicolumn{3}{c}{$\mathrm{PV}$} \\
\cline { 2 - 3 } Fluid type & $\mu_{0}(\mathrm{mPa} \mathrm{s})$ & $E_{\mathrm{a}}(\mathrm{J} / \mathrm{mol})$ & $R^{2}$ & & $\mu_{0}(\mathrm{mPa} \mathrm{s})$ & $E_{\mathrm{a}}(\mathrm{J} / \mathrm{mol})$ & $R^{2}$ \\
\hline Base fluid & 0.3799 & 10038.320 & 0.9966 & & 0.1662 & 11403.482 & 0.9965 \\
$0.25 \%$ MNC-OBDF & 1.0122 & 7742.579 & 0.9303 & & 0.5088 & 8684.804 & 0.9509 \\
$0.5 \%$ MNC-OBDF & 1.8543 & 6685.038 & 0.9234 & & 0.4325 & 9657.542 & 0.9662 \\
$1 \%$ MNC-OBDF & 3.4541 & 5406.012 & 0.9603 & & 1.0423 & 7559.671 & 0.9398 \\
$1.5 \%$ MNC-OBDF & 9.0676 & 3149.426 & 0.9901 & & 3.0674 & 4886.138 & 0.9991 \\
$2 \%$ MNC-OBDF & 12.5240 & 2665.552 & 0.9423 & & 3.7028 & 4869.759 & 0.9787 \\
$0.25 \%$ NG-OBDF & 0.5098 & 9415.605 & 0.9961 & & 0.2585 & 10445.710 & 0.9957 \\
$0.5 \%$ NG-OBDF & 0.8261 & 8297.621 & 0.9897 & & 0.2100 & 11223.070 & 0.9617 \\
$1 \%$ NG-OBDF & 0.7537 & 8722.217 & 0.9996 & & 0.3090 & 10380.030 & 0.9641 \\
$1.5 \%$ NG-OBDF & 0.4135 & 10601.180 & 1.0000 & & 0.3088 & 10628.620 & 0.9835 \\
$2 \%$ NG-OBDF & 1.3949 & 7775.835 & 0.9607 & & 1.0443 & 7812.915 & 0.9838 \\
\hline
\end{tabular}

By plotting AV values related to $1021.8 \mathrm{~s}^{-1}$ shear rate $v s$. inverse of the absolute temperatures in kelvin, $\mu_{0}$ and $E_{\mathrm{a}}$ as the Arrhenius parameters are calculated for AV of each of the studied drilling fluids. Figure 6 illustrates three examples of the plot for the base fluid, $2 \% \mathrm{MNC}-\mathrm{OBDF}$, and $2 \%$ NG-OBDF.

As listed in Table 4, all measured Regression coefficients related to AV values are in the range 0.9234-1.0000, so Arrhenius model is well applicable to clarify temperature dependency of $\mathrm{AV}$ of all drilling fluids. $2 \% \mathrm{MNC}-\mathrm{OBDF}$, $2 \%$ NG-OBDF, and the base fluid respectively have activation energies equal to $2665.552,7775.835$, and $10038.320 \mathrm{~J} / \mathrm{mol}$, so the arrangement of the studied fluids from the aspect of $\mathrm{AV}$ independency on temperature is total as following: MNC-OBDFs, NG-OBDFs, and the base fluid.

\subsection{Plastic viscosity}

Plastic Viscosity (PV) is one of the parameters of Bingham Plastic model. It is a part of the resistance against fluid flow and is due to the friction between the suspended particles and the base liquid viscosity [55]. Three major causes of friction are the collision of solid particles present in the fluid, the collision of the solids with their surrounding liquid, and motion/slippage of the liquid layers. According to the literature, organoclays and carbon-based NPs have the potential to enhance PV of drilling fluids. For example, more concentrations of PM199 and HDTMA-MMT organoclays provide higher PV for diesel oil [24]. By adding $17.5 \mathrm{~cm}^{3}$ of a lubricant of $\mathrm{NG}$ into a salt polymer mud, its PV increases from 12 to $16 \mathrm{mPa} \mathrm{s}$ [44].

As illustrated in Figure 7, both NPs act as viscosifier in the OBDF at all temperatures. Adding $2 \mathrm{wt} \% \mathrm{MNC}$ and NG into the base fluid, respectively, leads to $66.7 \%$ and $53.3 \%$ increase in the base PV at $90^{\circ} \mathrm{F}$. The justification is that by increasing the NPs concentration, the solid content in the base fluid increases, so the number of collisions of solid particles with themselves and the surrounding liquid phase increases and leads to more mechanical friction and consequent more PV over the base fluid. Like organomontmorillonite nanolayers in white oil [28], exfoliation of

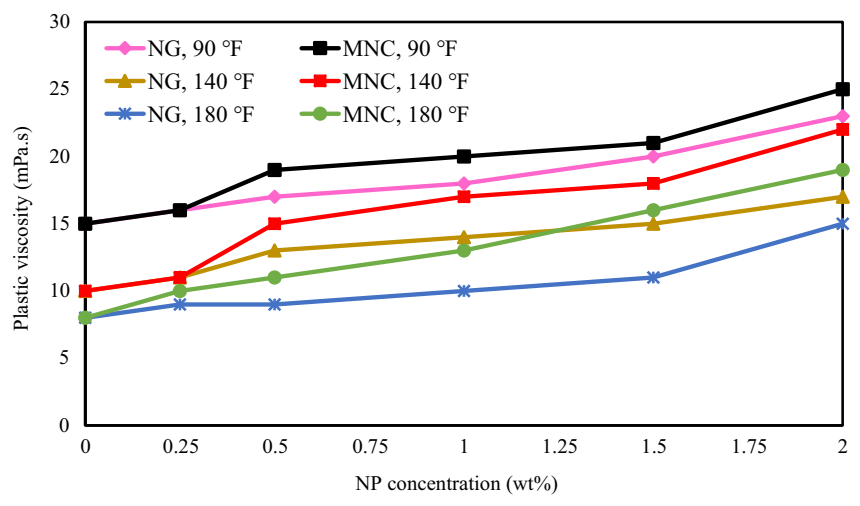

Fig. 7. Plastic viscosity as a function of temperature and NP concentration.

MNC nanolayers in diesel oil and their swelling shown in Figure 8, causes separation of the MNC nanolayers and providing higher mechanical friction over NG, so MNC is more effective than NG to increase PV. This finding confirms the conclusion reported by Brigatti et al. [56] and Shakib et al. [57]; clay NPs provide more significant PV in comparison to other additives.

Figure 9 shows the best-fitted trendlines of Arrhenius plot related to PV for $2 \%$ MNC-OBDF and $2 \%$ NG-OBDF compared to the plot for the base fluid. Besides, the modeled Arrhenius parameters and their related Regression values for all drilling fluids have been listed in Table 4. High $R$-squared values $(>0.9398)$ reveal that Arrhenius model is suitable to describe temperature dependency of PV of all fluids investigated in this study. As listed in Table 3, activation energies of all NP-OBDFs are fewer than that of the base fluid (11403.480 J/mol). Two percent MNC-OBDF has the minimum activation energy among all drilling fluids (4869.759 J/mol), and the minimum activation energy among the NG-OBDFs belongs to $2 \%$ NG-OBDF (7812.915). So, the arrangement of PV independency on temperature for the studied fluids is as MNC-OBDFs, NG-OBDFs, and the base fluid. To clarify the discussion, 


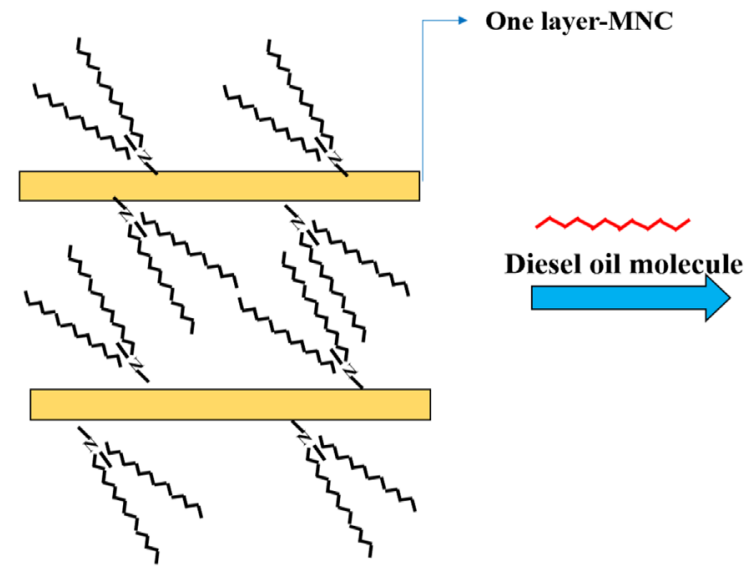

Dry MNC

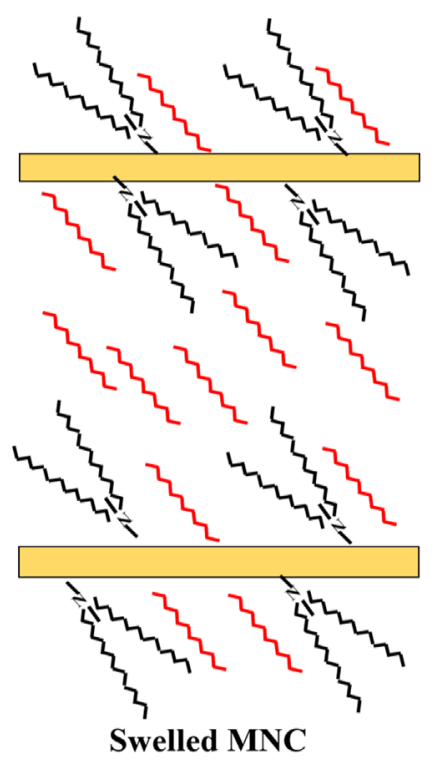

Fig. 8. Interaction of MNC nanolayers with diesel oil.

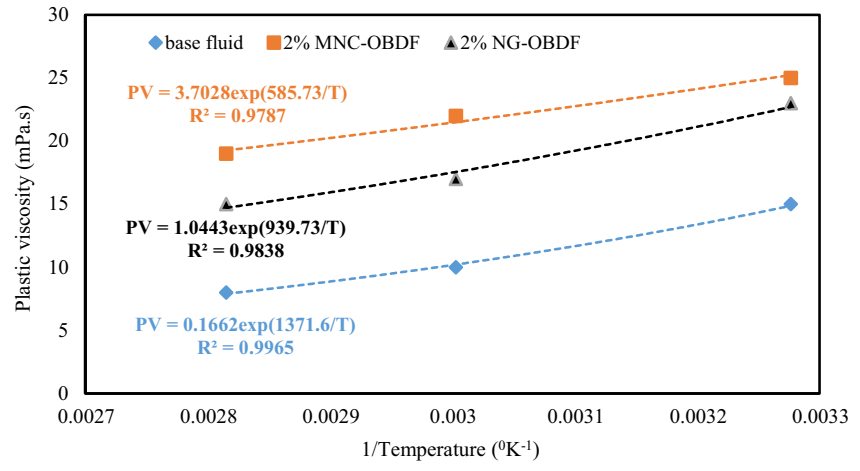

Fig. 9. Arrhenius plot related to $\mathrm{PV}$ for the base fluid, $2 \%$ MNC-OBDF, and $2 \%$ NG-OBDF.

as temperature increases from $90{ }^{\circ} \mathrm{F}$ to $180{ }^{\circ} \mathrm{F}, \mathrm{PV}$ of $2 \%$ MNC-OBDF decreases from $25 \mathrm{mPa}$ s to $19 \mathrm{mPa} \mathrm{s}$ (24\% reduction), $\mathrm{PV}$ of $2 \%$ NG-OBDF decreases from $23 \mathrm{mPa}$ s to $15 \mathrm{mPa} \mathrm{s}(34.8 \%$ reduction $)$ and the base $\mathrm{PV}$ is reduced from $15 \mathrm{mPa}$ s to $8 \mathrm{mPa} \mathrm{s}$ (46.7\% reduction). In a sentence, MNC is preferred over NG to be used as viscosifier even at high temperatures, but more pumping pressure is required to circulate $\mathrm{MNC}-\mathrm{OBDF}$ s in the drilling fluid circulation system.

\subsection{Yield point and gel strength}

Yield Point (YP) is the other parameter of Bingham Plastic model that resists against fluid flow [55]. A Bingham plastic drilling fluid requires a minimum shear stress to be placed at the flow threshold. This minimum shear stress is called YP [58]. YP of a drilling fluid is a sign of electrostatic attraction forces among its particles at dynamic conditions to suspend drilling cuttings against falling to bottomhole. $\mathrm{YP}$ is a function of three factors: surface properties of the drilling fluid, solids volumetric concentration, and concentration and types of the ions present in the fluid [59].

As listed in Table 5, YP of the studied drilling fluids at all temperatures overall is proportional to the NPs concentration, but there are some anomalies in the trends. Because of the invasion of diesel oil among MNC dry nanolayers and consequent MNC particles swelling and providing more solid content in the base fluid, MNC provides greater YP over NG at all concentrations and temperatures, so MNC is the best NP to suspend cuttings during drilling. Also, according to Field Emission Scanning Electron Microscopy (FESEM) images of MNC and NG which have been respectively shown in Figures 10a and 10b, both NPs have flatlike shapes which resist better than spherical particles against fall of cuttings; this is an important feature for keeping drilling cuttings suspended. As temperature increases from $90{ }^{\circ} \mathrm{F}$ up to 140 , and $180{ }^{\circ} \mathrm{F}$, YP of the base fluid decreases from 4.780 to 3.824 and $3.346 \mathrm{~Pa}$, but there is no specific relation between $\mathrm{YP}$ and temperature for all NP-OBDFs. $1.5 \%$ MNC-OBDF and 2\% MNC-OBDF at all temperatures have significant YPs, which indicates strong electrostatic forces among their particles even at high temperatures. If the high yielding tendency of these MNC-OBDFs limits their operational application, deflocculants could be added into them to reduce their YPs without any effect on their PVs [60].

Gel Strength (GS) of drilling fluid, as its thixotropic indicator, is a measurement of the attraction forces among its particles at static conditions. GS is essential to ensure the suspension of cuttings in case of stopped drilling. As listed in Table 5, addition of both NPs into the base fluid leads to improving its initial GS at all temperatures. Maximum GS-10 s among all NP-OBDFs at the three temperatures belongs to $2 \% \mathrm{MNC}-\mathrm{OBDF}$. The trend of initial GS of NG-OBDFs vs. temperature is overall similar to that of the base fluid (as temperature increases, GS-10 s decreases). However, the effect of temperature increase on 
Table 5. Yield point and gel strength of the fluids at various temperatures (accuracy: $1 \mathrm{lb} / 100 \mathrm{ft}^{2}=0.478 \mathrm{~Pa}$ ).

\begin{tabular}{|c|c|c|c|c|c|c|c|c|c|}
\hline \multirow[b]{2}{*}{ Temperature $\left({ }^{\circ} \mathrm{F}\right)$} & \multicolumn{3}{|c|}{$\mathrm{YP}(\mathrm{Pa})$} & \multicolumn{3}{|c|}{ GS-10 s (Pa) } & \multicolumn{3}{|c|}{ GS-10 $\min (\mathrm{Pa})$} \\
\hline & 90 & 140 & 180 & 90 & 140 & 180 & 90 & 140 & 180 \\
\hline Base fluid & 4.780 & 3.824 & 3.346 & 2.868 & 1.912 & 1.434 & 3.346 & - & - \\
\hline $0.25 \%$ MNC-OBDF & 5.736 & 4.302 & 4.302 & 3.824 & 3.346 & 2.390 & 4.302 & - & - \\
\hline $0.5 \%$ MNC-OBDF & 7.170 & 4.302 & 7.170 & 3.904 & 3.346 & 3.824 & 4.780 & - & - \\
\hline $1 \% \mathrm{MNC}-\mathrm{OBDF}$ & 9.082 & 6.214 & 8.604 & 4.780 & 3.824 & 4.302 & 5.736 & - & - \\
\hline $1.5 \% \mathrm{MNC}-\mathrm{OBDF}$ & 10.038 & 9.560 & 10.038 & 5.736 & 4.780 & 4.780 & 6.692 & - & - \\
\hline $2 \%$ MNC-OBDF & 10.038 & 10.994 & 10.994 & 6.214 & 5.736 & 5.258 & 7.170 & - & - \\
\hline $0.25 \%$ NG-OBDF & 4.780 & 3.824 & 3.346 & 3.346 & 2.390 & 1.912 & 3.346 & - & - \\
\hline $0.5 \%$ NG-OBDF & 4.302 & 3.824 & 4.302 & 3.346 & 2.868 & 2.390 & 3.824 & - & - \\
\hline $1 \%$ NG-OBDF & 5.258 & 3.346 & 4.302 & 3.824 & 3.346 & 2.868 & 4.302 & - & - \\
\hline $1.5 \%$ NG-OBDF & 6.692 & 3.824 & 3.824 & 4.302 & 3.824 & 2.868 & 4.780 & - & - \\
\hline $2 \%$ NG-OBDF & 7.170 & 4.780 & 4.780 & 4.780 & 3.824 & 3.346 & 5.736 & - & - \\
\hline
\end{tabular}

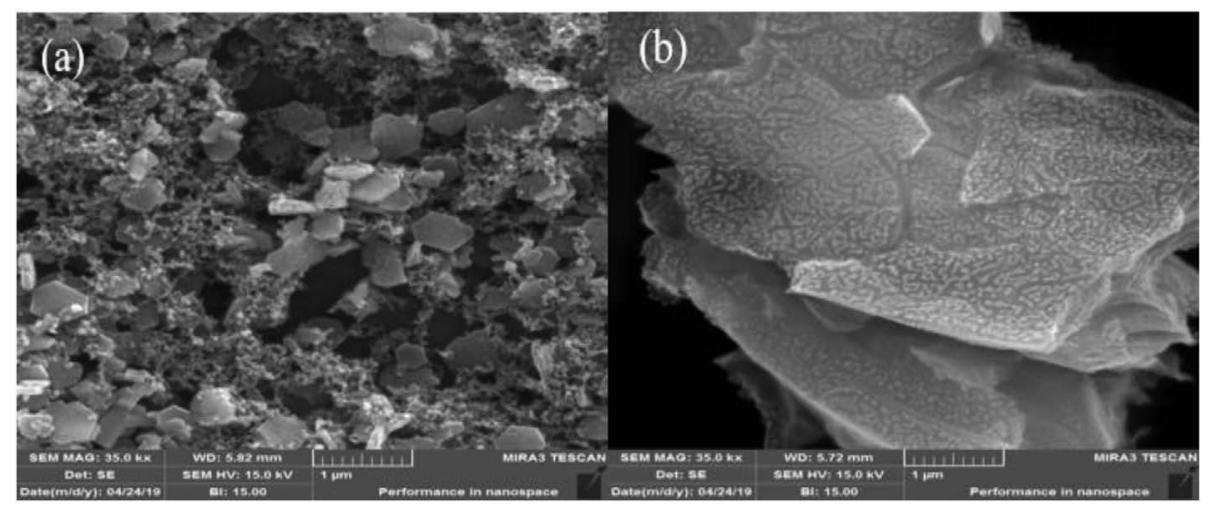

Fig. 10. FESEM image of (a) MNC, (b) NG.

initial GS of the MNC-OBDFs is more complex and does not follow a particular trend. As listed in Table 5 , by adding $2 \mathrm{wt} \% \mathrm{MNC}$ and $\mathrm{NG}$ into the base fluid at $90^{\circ} \mathrm{F}$, the base GS-10 $\mathrm{min}$ is increased respectively by 114 and $71 \%$. Finally, MNC enhances gelation properties of the OBDF more than NG, so it is the preferred NP for having a better cutting suspension at static conditions.

\subsection{Electrical or emulsion stability}

Water droplets are stabilized in the oil phase of an OBDF by the first and second emulsifiers present in the OBDF's formulation. According to Parsons and Wilson definition, those water-in-oil and oil-in-water emulsions, which are stabilized by an emulsifying agent, are considered as true emulsions [61]. Electrical stability of an OBDF is the indicator of its water-in-oil emulsion stability; the higher critical voltage is the sign of the higher emulsion stability and better dispersion of water droplets in the oil phase. The critical voltage, which corresponds to the emulsion stability, is achieved while a fixed electrical current, equal to $61 \mu \mathrm{A}$, is established in the fluid.
As can be seen in Figure 11, as MNC concentration in the base fluid increases, the electrical stability of the OBDF increases more at $90^{\circ} \mathrm{F}$, consequently. According to Ghosn et al. discussions, this proportional relation between MNC concentration and ES can be due to the increasing adsorption rate of MNC particles at the oil-water interface as well as lowering the size of the liquid droplets and preventing their coalescence [62]. Indeed, MNC is produced through replacing some cations located on the bentonite surface (i.e., $\mathrm{Mg}^{2+}$ and $\mathrm{Ca}^{2+}$ ) by several quaternary ammonium cations, namely bis (hydrogenated tallow alkyl) dimethyl cations consisting of two methyls and two Hydrogenated Tallow Alkyl (HTA) groups. Figure 12 shows a simple structural formula for MNC. The relative negative charge of bentonite surface has been introduced to show the removal of some positive charges from bentonite nanolayers. As graphically shown in Figure 13, the two hydrophobic HTA long chains located on the bentonite surface link to the diesel oil molecules and bentonite clay (which is hydrophilic due to the presence of $\mathrm{Si}-\mathrm{O}, \mathrm{Al}-\mathrm{O}$, and $\mathrm{Mg}-\mathrm{O}$ bonds), links to water molecules; so, according to Jha et al. study [63], Interfacial Tension (IFT) between 


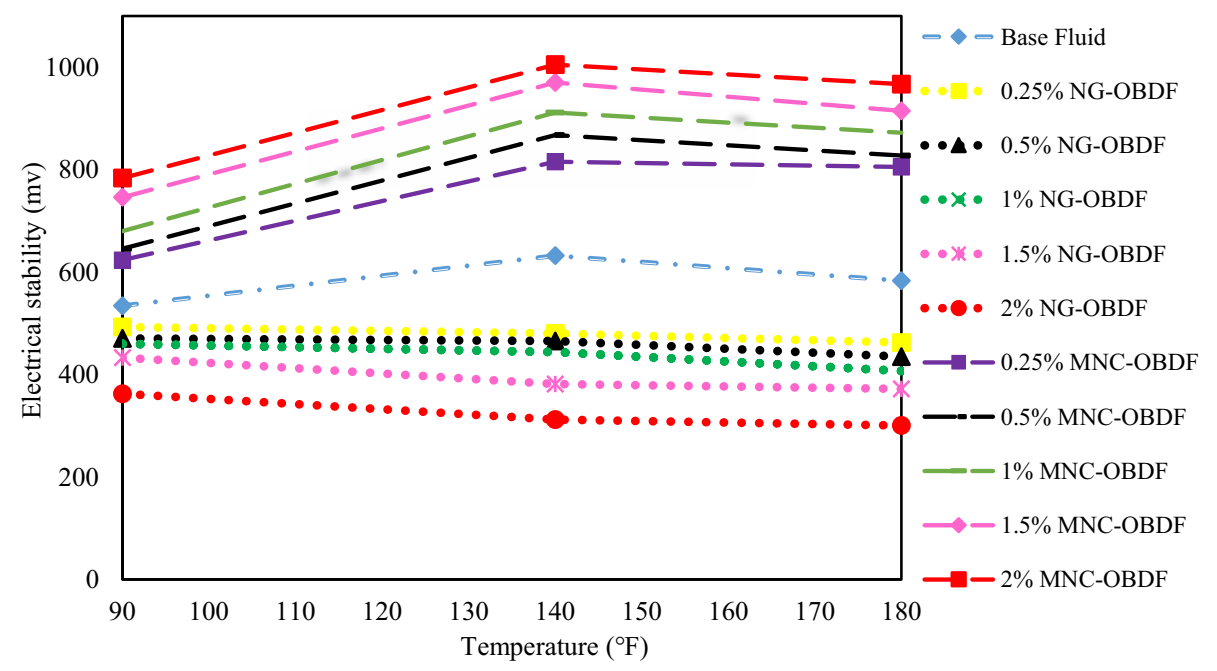

Fig. 11. Electrical stability of the fluids at different temperatures.

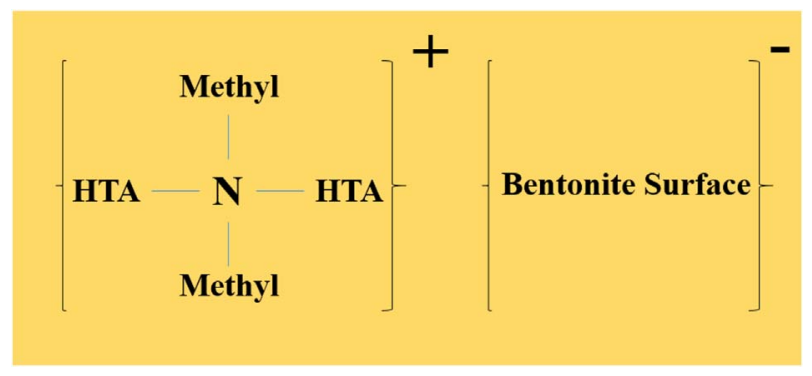

Fig. 12. A simple structural formula of MNC.

the two immiscible liquids decreases and causes more dispersion of water droplets in the oil phase as well as more decreasing in the water droplets' size and consequent providing a more stable emulsion. Establishing an electrical current of $61 \mu \mathrm{A}$ through completing the electrical circuit by merging the smaller water droplets in the MNC-OBDFs, compared to joining the coarser water droplets in the base fluid, requires a more potent electrical force. According to equation (8), when a more electrical force is required for applying on a constant electrical charge, the magnitude of the electrical field around the charge must be increased. Also, as equation (9) shows, increasing the electrical field between two fixed plates (probes of ES meter, here) causes increasing the threshold voltage between them. Hence, the critical voltage in MNC-OBDFs is higher than the base critical voltage:

$$
\begin{aligned}
& F=E \times q, \\
& E=V \times \frac{1}{d} .
\end{aligned}
$$

In SI system, $F$ is the electrical force in N, $E$ is the magnitude of electrical filed in $\mathrm{N} / \mathrm{C}, q$ is the electrical charge of particles in C, $V$ is the voltage in volt, and $d$ is the distance between two metal plates of the ES meter.
Contrary to the MNC-OBDFs, addition of NG particles results in decreasing electrical stability of the base fluid at $90{ }^{\circ} \mathrm{F}$. For example, electrical stability of $2 \%$ NG-OBDF is $32.2 \%$ less than the base fluid at $90^{\circ} \mathrm{F}$. The justification of the negative effect of NG on electrical stability is that, when an ascending electrical filed is applied to the NG-OBDFs, the NG particles with a high degree of hydrophobicity (due to the significant presence of $\mathrm{C}-\mathrm{H}$ and $\mathrm{C}-\mathrm{C}$ bonds) and electrical conductivity, form another one electrical circuit in the oil phase quicker and independent of the water-wet droplets, so the electrical current is established at a weaker electrical filed and consequent a less electrical voltage.

As illustrated in Figure 11, hot rolling leads to increasing electrical stability of the base fluid and MNC-OBDFs at both temperatures 140 and $180{ }^{\circ} \mathrm{F}$. This result is per Ali et al. finding [64]; the effect of hot rolling on electrical stability of OBDFs is consistent with field experience, which is: the electrical stability of OBDFs increases after a few circulations through bit nozzles. The magnitude of electrical stability of the MNC-OBDFs and the base fluid at $140{ }^{\circ} \mathrm{F}$ is more than that at $180^{\circ} \mathrm{F}$. This finding could be due to better performance of the commercial first and second emulsifiers for emulsification at $140^{\circ} \mathrm{F}$ than that at $180^{\circ} \mathrm{F}$. Also, by considering the curves of ES vs. temperature at both temperature ranges $90-140^{\circ} \mathrm{F}$ and $140-180{ }^{\circ} \mathrm{F}$, it is evident that the rate of increasing ES in the first temperature range is higher and also the rate of decreasing ES in the second range is lower for all MNC-OBDFs compared to the base fluid; hence ES of the MNC-OBDFs is thermally more stable than the base fluid which reveals MNC particles' ability for supporting the commercial emulsifiers at a variety of temperatures. Organoclays are potential additives to form pickering emulsions [65-67]; any emulsion stabilized by solid particles instead of surfactants [68]. Accordingly, considering the appropriate performance of MNC for better stabilization of water-in-oil emulsion in the base fluid of this study, it could probably be a suitable additive to form stable water-in-oil pickering emulsion. So, MNC could be of interest to pickering emulsion researchers. 


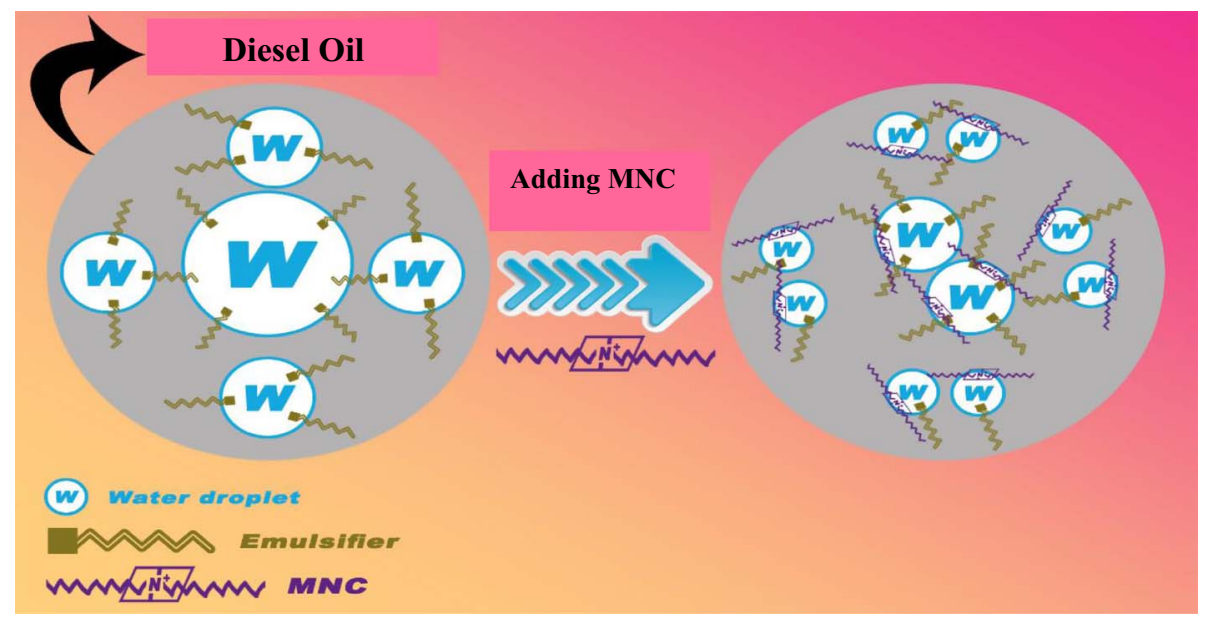

Fig. 13. Schematic of reducing water droplets size using MNC.

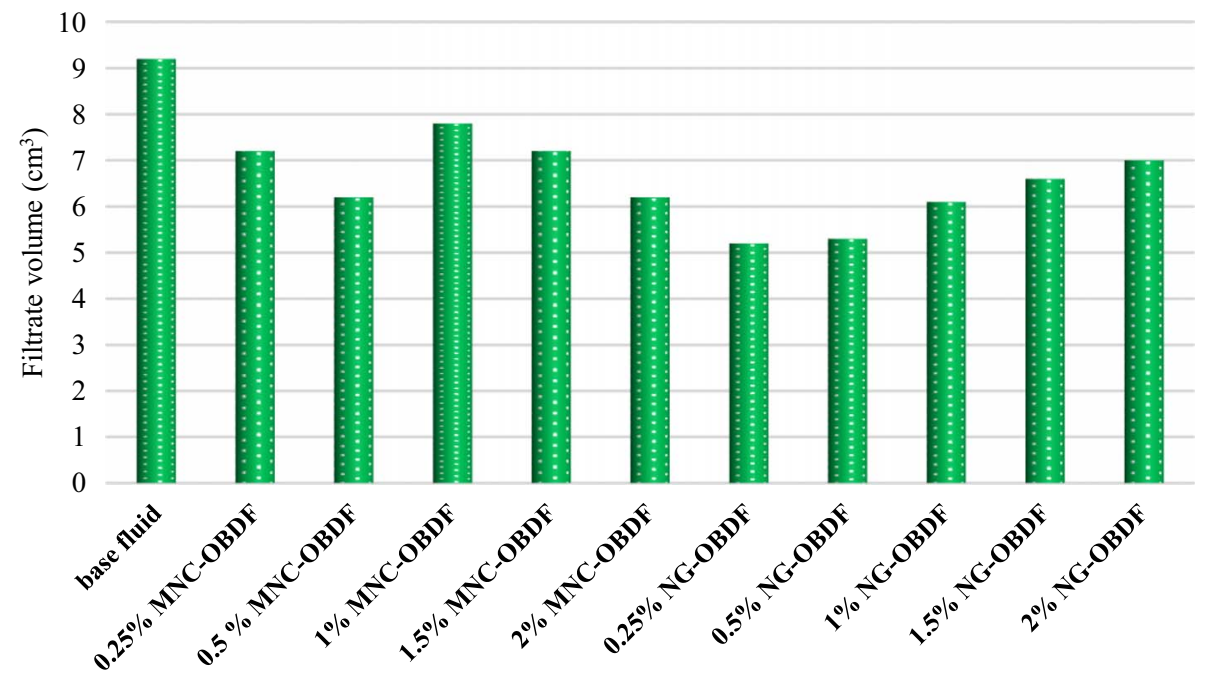

Fig. 14. Filtrate volume of the drilling fluids at HPHT conditions.

As illustrated in Figure 11, hot rolling leads to decreasing emulsion stability of the NG-OBDFs at both temperatures 140 and $180{ }^{\circ} \mathrm{F}$ in comparison to that at $90{ }^{\circ} \mathrm{F}$. Increasing temperature causes increasing electrical conductivity of carbon-based materials like Graphite and carbon particles [69]. NG particles are carbon-based, and they are similar to graphite in the aspect of having layered structures. Hence, temperature increase during hot rolling leads to increase electrical conductivity of the NG-OBDFs and consequent, reducing their electrical resistivity. Finally, according to Ohm's law (Eq. (10)), it is required to apply a less voltage for establishing the constant electrical current in a circuit with less electrical resistivity. So, as temperature increases, the stability of the water-in-oil emulsion present in NG-OBDFs decreases:

$$
R=\frac{V}{I}
$$

In SI system, $V$ : voltage in volt, $I$ : electrical current in Ampere (A) and $R$ is electrical resistivity in ohm.

\subsection{HPHT filtration}

Controlling filtration loss as a vital property of drilling fluids reduces the chance of formation damage and its associated operating costs [70]. Quickly formation of a thin filter cake on porous and permeable formations is necessary to minimize or even avoid fluid loss into them [71]. As presented in Figure 14, the filtrate volume of all NP-OBDFs under 500 psi differential pressure and $300{ }^{\circ} \mathrm{F}$ temperature is less than that of the base fluid $\left(9.2 \mathrm{~cm}^{3}\right)$, which illustrates the both NPs supporting role to form less-permeable mud cakes. The ability of both NPs to reduce filtration loss is probably related to their flat-like shapes that could be operationally helpful in coating the pores located on the wellbore wall. Investigating filtrate volume as a function of NG concentration shows that base filtrate volume is reduced by $43.5 \%, 42.4 \%$, and $33.7 \%$ respectively in cases of $0.25,0.5$, and $1 \mathrm{wt} \% \mathrm{NG}$ which are the best cases among all studied drilling fluids from controlling filtration into formation aspect. Adding 1.5 and $2 \mathrm{wt} \% \mathrm{NG}$ concentrations 


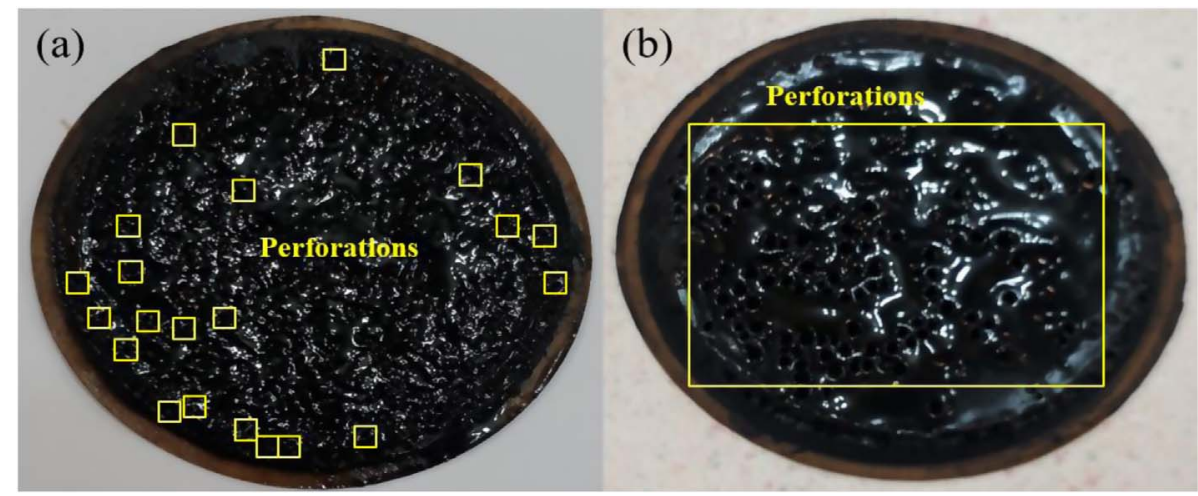

Fig. 15. Mud cake of (a) $1.5 \%$ NG-OBDF, (b) $2 \%$ NG-OBDF.

into the base fluid caused the creation of some deep perforations in the mud cakes' structures that have been respectively shown in Figures 15a and 15b, so the less NG contents are more confident from the aspect of supporting the commercial filtration control agent. Investigation of MNC impact on filtration loss shows that the maximum filtrate volume reduction among all MNC-OBDFs is $32.6 \%$, which belongs to both $0.5 \mathrm{wt} \%$ and $2 \mathrm{wt} \%$ MNC concentrations, so $0.5 \mathrm{wt} \% \mathrm{MNC}$ is technically and economically the optimum MNC concentration for supporting the commercial filtration control agent.

As Goud and Joseph (2006) mentioned, fracture creation during drilling operation in a small operational window between pore and fracture pressures is a common problem that leads to more loss circulation and consequent more operating costs. Sealing the fractures in a wellbore is called wellbore strengthening. They used graphite particles to seal fractures for wellbore strengthening [66]. Hexagonal lattice of carbon atoms in NG structure likes it in graphite. Hence, NG is highly flexible, and in addition to NG particles' ability to control filtration, they can probably seal the fractures and, consequently, reduce operational costs.

\section{Conclusion}

Experimental findings: (1) All NP-OBDFs, follow well Herschel Bulkley model with shear-thinning properties. (2) Bingham Plastic model accuracy is only 1.68 lesser than Herschel Bulkley model for predicting rheological behavior of the studied drilling fluids. (3) MNC is more applicable than NG for enhancing rheological properties of the base fluid, including its apparent viscosity, plastic viscosity, yield point, and gel strength. (4) According to the activation energies calculated from Arrhenius model, thermal stability of apparent viscosity and plastic viscosity of MNC-OBDFs overall is more than NG-OBDFs. (5) MNC particles with amphiphilic nature provide higher emulsion stability over the base fluid, but the NG particles due to their high electrical conductivity reduce the water-in-oil emulsion stability. (6) $0.25 \%$ NG-OBDF has the minimum fluid loss among all studied drilling fluids (43.5\% lesser than the base fluid), and $0.5 \mathrm{wt} \%$ is the optimum MNC concentration from reducing filtration into formation aspect.
Engineering point of view: from the operational feasibility of using the NPs in OBDFs' formulation aspect, MNC particles can be used as a supporting agent for commercial additives of OBDFs, including their viscosifiers, emulsifiers, and fluid loss control agents; however, pumping pressure limitation must be considered. Low contents of NG particles can be used as a supporting agent for commercial viscosifier, and filtration control agent, but the emulsion stability reduction must be managed. Despite the improvement of rheological and filtration control properties by using high NG concentrations, stability of the water-in-oil emulsion decreases so much that makes it impossible operationally to use OBDFs containing high NG contents. Finally, MNC is applicable to design nano-enhanced OBDFs, but NG is limited to design nano-enhanced OBDFs.

Acknowledgments. The authors appreciate the Naft Gostar Company Management and Engineering team in Ahwaz city for their cooperation in this academic research.

\section{References}

1 William J.K.M., Ponmani S., Samuel R., Nagarajan R., Sangwai J.S. (2014) Effect of $\mathrm{CuO}$ and $\mathrm{ZnO}$ nanofluids in xanthan gum on thermal, electrical and high pressure rheology of water-based drilling fluids, J. Pet. Sci. Eng. 117, 15-27.

2 Shahbazi K. (2006) Oxidation and rheological aspects of oil and synthetic-based drilling fluids at elevated pressures and temperatures, Doctoral thesis, Uinversity of Calgary, Calgary.

3 Al-Sabagh A., Noor El-Din M., Mohamed H. (2009) Oil Base Mud. Part I: Synthesis of some local surfactants used as primary emulsifiers for oil base mud and evaluation of their rheology properties, J. Dispers. Sci. Technol. 30, 7, 1079-1090.

4 Halali M.A., Ghotbi C., Tahmasbi K., Ghazanfari M.H. (2016) The role of carbon nanotubes in improving thermal stability of polymeric fluids: Experimental and modeling, Indus. Eng. Chem. Res. 55, 27, 7514-7534.

5 Madkour T.M., Fadl S., Dardir M., Mekewi M.A. (2016) High performance nature of biodegradable polymeric nanocomposites for oil-well drilling fluids, Egyptian J. Pet. 25, 2, 281-291.

6 Agarwal S., Tran P., Soong Y., Martello D., Gupta R.K. (2011) Flow behavior of nanoparticle stabilized drilling fluids and effect of high temperature aging, in AADE National Technical Conference and Exhibition, Houston, pp. 12-14. 
7 Ozbayoglu M.E., Saasen A., Sorgun M., Svanes K. (2008) Effect of pipe rotation on hole cleaning for water-based drilling fluids in horizontal and deviated wells, in $I A D C / S P E$ Asia Pacific Drilling Technology Conference and Exhibition, Society of Petroleum Engineers.

8 Abduo M., Dahab A., Abuseda H., AbdulAziz A.M., Elhossieny M. (2016) Comparative study of using waterbased mud containing multiwall carbon nanotubes versus oilbased mud in HPHT fields, Egyptian J. Pet. 25, 4, 459-464.

9 El-Diasty A.I., Ragab A.M.S. (2013) Applications of nanotechnology in the oil \& gas industry: Latest trends worldwide \& future challenges in Egypt, in North Africa Technical Conference and Exhibition, Society of Petroleum Engineers.

10 Li K., Wang D., Jiang S. (2018) Review on enhanced oil recovery by nanofluids, Oil Gas Sci. Technol. - Rev. IFP Energies nouvelles $\mathbf{7 3}, 37$.

11 Shchukin D.G., Sukhorukov G.B.J.A.M. (2004) Nanoparticle synthesis in engineered organic nanoscale reactors, J. $A d v$ Mater. 16, 8, 671-682.

12 Godson L., Raja B., Lal D.M., Wongwises S. (2010) Enhancement of heat transfer using nanofluids - an overview, J. Renewable Sustainable Energy 14, 2, 629-641.

13 Rao Y. (2010) Nanofluids: stability, phase diagram, rheology and applications, Particuology Journal 8, 6, 549-555.

14 Qalandari R., Qalandari E. (2018) A review on the potential application of nano graphene as drilling fluid modifier in petroleum industry, Int. Refereed J. Eng. Sci. (IRJES) 07, 1-7.

15 Shadravan A., Amani M. (2012) HPHT 101: What every engineer or geoscientist should know about high pressure hightemperature wells, in: SPE Kuwait International Petroleum Conference and Exhibition, Society of Petroleum Engineers.

16 Jordan J.W., Hook B., Finlayson C. (1950) The Organophilic Bentonites. II. Organic Liquid Gels, J. Phys. Chem. 54, 8, 1196-1208.

17 Hato M.J., Zhang K., Ray S.S., Choi H.J. (2011) Rheology of organoclay suspension, Colloid Polym. Sci. 289, 10, 1119.

18 De Paiva L.B., Morales A.R., Díaz F.R.V. (2008) Organoclays: properties, preparation and applications, Appl. Clay Sci. 42, 1-2, 8-24.

19 King H. Jr., Milner S.T., Lin M.Y., Singh J.P., Mason T. (2007) Structure and rheology of organoclay suspensions, Phys. Rev. E 75, 2, 021403.

20 Hermoso J., Martínez-Boza F.J., Gallegos C. (2017) Modeling pressure-viscosity behavior of oil-based drilling fluids, Oil Gas Sci. Technol. - Rev. IFP Energies nouvelles 72, 4, 18.

21 Zhuang G., Gao J., Peng S., Zhang Z. (2019) Synergistically using layered and fibrous organoclays to enhance the rheological properties of oil-based drilling fluids, Appl. Clay Sci. 172, 40-48.

22 Zhuang G., Zhang Z., Peng S., Gao J., Jaber M. (2018) Enhancing the rheological properties and thermal stability of oil-based drilling fluids by synergetic use of organomontmorillonite and organo-sepiolite, Appl. Clay Sci. 161, 505-512.

23 Zhuang G., Zhang Z., Jaber M. (2019) Organoclays used as colloidal and rheological additives in oil-based drilling fluids: An overview, Appl. Clay Sci. 177, 63-81.

24 Ghavami M., Hasanzadeh B., Zhao Q., Javadi S., Kebria D.Y. (2018) Experimental study on microstructure and rheological behavior of organobentonite/oil-based drilling fluid, J. Mol. Liq. 263, 147-157.
25 Agarwal S., Phuoc T.X., Soong Y., Martello D., Gupta R.K. (2013) Nanoparticle-stabilised invert emulsion drilling fluids for deep-hole drilling of oil and gas, Can. J. Chem. Eng. 91, $10,1641-1649$.

26 Zhuang G., Wu H., Zhang H., Zhang Z., Zhang X., Liao L. (2017) Rheological properties of organo-palygorskite in oilbased drilling fluids aged at different temperatures, Appl. Clay Sci. 137, 50-58.

27 Hermoso J., Martinez-Boza F., Gallegos C. (2014) Influence of viscosity modifier nature and concentration on the viscous flow behaviour of oil-based drilling fluids at high pressure, Appl. Clay Sci. 87, 14-21.

28 Zhuang G., Zhang H., Wu H., Zhang Z., Liao L. (2017) Influence of the surfactants' nature on the structure and rheology of organo-montmorillonite in oil-based drilling fluids, Appl. Clay Sci. 135, 244-252.

29 Fazelabdolabadi B., Khodadadi A.A., Sedaghatzadeh M. (2015) Thermal and rheological properties improvement of drilling fluids using functionalized carbon nanotubes, Appl. Nanosci. 5, 6, 651-659.

30 Yearsley K.M., Mackley M.R., Chinesta F., Leygue A. (2012) The rheology of multiwalled carbon nanotube and carbon black suspensions, J. Rheol. 56, 6, 1465-1490.

31 Yang Y., Grulke E.A., Zhang Z.G., Wu G. (2006) Thermal and rheological properties of carbon nanotube-in-oil dispersions, J. Appl. Phys. 99, 11, 114307.

32 Nasser J., Jesil A., Mohiuddin T., Al Ruqeshi M., Devi G., Mohataram S. (2013) Experimental investigation of drilling fluid performance as nanoparticles, World J. Nano Sci. Eng. 3, 03,57 .

33 Ho C.Y., Yusup S., Soon C.V., Arpin M.T. (2016) Rheological behaviour of graphene nano-sheets in hydrogenated oil-based drilling fluid, Procedia Eng. 148, 49-56.

34 Chai Y.H., Yusup S., Chok V.S., Irawan S., Singh J., Chin B. (2017) Comparison of rheological properties of graphene/ carbon nanotube hydrogenated oil based biodegradable drilling fluid, in: IOP Conference Series: Materials Science and Engineering, Vol. 206, IOP Publishing, p. 012042.

35 Ribeiro J.M., Eler F.M., Martins A.L., Scheid C.M., Calçada L.A., da Cruz Meleiro L.A. (2017) A simplified model applied to the barite sag and fluid flow in drilling muds: Simulation and experimental results, Oil Gas Sci. Technol. - Rev. IFP Energies nouvelles $\mathbf{7 2}, 4,23$.

36 Magalhães S., Calçada L., Scheid C., Almeida H., Waldmann A. (2016) Improving drilling performance with continuous online measurements of electrical stability and conductivity in oil based drilling fluids, J. Pet. Sci. Eng. 146, 369-379.

37 Fingas M., Fieldhouse B. (2003) Studies of the formation process of water-in-oil emulsions, Marine Pollut. Bull. 47, 9-12, 369-396.

38 Pal R. (1994) Techniques for measuring the composition (oil and water content) of emulsions - a state of the art review, Colloids Surf. A Physicochem. Eng. Aspects 84, 2-3, 141-193.

39 Crittendon B.C. (1958) Device for measuring stability of water-in-oil emulsion, ed: Google Patents.

40 Messenger J. (1965) Emulsion control using electrical stability potential, J. Pet. Technol. 17, 10, 1229-1231.

41 Growcock F., Ellis C., Schmidt D., Azar J. (1994) Electrical stability, emulsion stability, and wettability of invert oilbased muds, SPE Drill. Complet. 9, 01, 39-46. 
42 Yusof M.A.M., Hanafi N.H. (2015) Vital roles of nano silica in synthetic based mud for high temperature drilling operation, in: AIP Conference Proceedings, Vol. 1669, AIP Publishing, p. 020029.

43 Fink J. (2015) Petroleum engineer's guide to oil field chemicals and fluids, Gulf Professional Publishing.

44 Taha N.M., Lee S. (2015) Nano graphene application improving drilling fluids performance, in: International Petroleum Technology Conference, 6-9 December, Doha, Qatar.

45 Devereux S. (1998) Practical well planning and drilling manual, PennWell Books.

46 Rahmati A.S., Tatar A. (2019) Application of Radial Basis Function (RBF) neural networks to estimate oil field drilling fluid density at elevated pressures and temperatures, Oil Gas Sci. Technol. - Rev. IFP Energies nouvelles 74, 50.

47 Fagundes F.M., Santos N.B., Damasceno J.J.R., Arouca F.O. (2018) Study on the stability of a shear-thinning suspension used in oil well drilling, Oil Gas Sci. Technol. Rev. IFP Energies nouvelles 73, 10.

48 Parizad A., Ghahfarokhi A.K., Shahbazi K., Daryasafar A., Sayahi T., Meybodi M.K. (2019) Experimental investigation of the effect of $\mathrm{TiO}_{2}$ nanofluid and $\mathrm{KCl}$ salt on polymeric water-based drilling fluid properties, Oil Gas Sci. Technol. Rev. IFP Energies nouvelles 74, 9.

49 Hermoso J., Martínez-Boza F., Gallegos C. (2014) Combined effect of pressure and temperature on the viscous behaviour of all-oil drilling fluids, Oil Gas Sci. Technol. - Rev. IFP Energies nouvelles 69, 7, 1283-1296.

50 Rafati R., Smith S.R., Haddad A.S., Novara R., Hamidi H. (2018) Effect of nanoparticles on the modifications of drilling fluids properties: a review of recent advances, J. Pet. Sci. Eng. 161, 61-76.

51 Meng X., Zhang Y., Zhou F., Chu P.K. (2012) Effects of carbon ash on rheological properties of water-based drilling fluids, J. Pet. Sci. Eng. 100, 1-8.

52 Al-Mahdawi F.H., Saad K. (2018) Enhancement of Drilling Fluid Properties Using Nanoparticles, Iraqi J. Chem. Pet. Eng. 19, 2, 21-26.

53 Khalil M., Jan B.M., Raman A.A.A. (2011) Rheological and statistical evaluation of nontraditional lightweight completion fluid and its dependence on temperature, J. Pet. Sci. Eng. 77, 1, 27-33.

54 Falcone P.M., Chillo S., Giudici P., Del Nobile M.A. (2007) Measuring rheological properties for applications in quality assessment of traditional balsamic vinegar: description and preliminary evaluation of a model, J. Food Eng. 80, 1, 234-240.

55 Falode O., Ehinola O., Nebeife P. (2008) Evaluation of local bentonitic clay as oil well drilling fluids in Nigeria, Appl. Clay Sci. 39, 1-2, 19-27.

56 Brigatti M.F., Galan E., Theng B. (2006) Structures and mineralogy of clay minerals, Dev. Clay Sci. 1, 19-86.
57 Shakib J.T., Kanani V., Pourafshary P. (2016) Nano-clays as additives for controlling filtration properties of waterbentonite suspensions, J. Pet. Sci. Eng. 138, 257-264.

58 Bourgoyne A.T. Jr., Millheim K.K., Chenevert M.E., Young F.S. Jr. (1986) Applied drilling engineering, Vol. 2, Society of Petroleum Engineers.

59 Amoco-Production-Company (2010) Drilling fluids manual.

60 Moslemizadeh A., Shadizadeh S.R., Moomenie M. (2015) Experimental investigation of the effect of henna extract on the swelling of sodium bentonite in aqueous solution, Appl. Clay Sci. J. 105, 78-88.

61 Parsons L.W., Wilson O. Jr. (1921) Some Factors Affecting the Stability and Inversion of Oil-Water Emulsions, Indus. Eng. Chem. 13, 12, 1116-1123.

62 Ghosn R., Mihelic F., Hochepied J.-F., Dalmazzone D. (2017) Silica nanoparticles for the stabilization of $\mathrm{W} / \mathrm{O}$ emulsions at HTHP conditions for unconventional reserves drilling operations, Oil Gas Sci. Technol. - Rev. IFP Energies nouvelles $\mathbf{7 2}, 4,21$.

63 Jha P.K., Mahto V., Saxena V. (2014) Emulsion based drilling fluids: an overview, Int. J. ChemTech. Res. 6, 4, 2306-2315.

64 Ali A., Schmidt D., Harvey J., III (1987) Investigation of the electrical stability test for oil muds, in: SPE/IADC Drilling Conference, Society of Petroleum Engineers.

65 Zheng B., Zheng B., Carr A.J., Yu X., McClements D.J., Bhatia S.R. (2020) Emulsions stabilized by inorganic nanoclays and surfactants: stability, viscosity, and implications for applications, Inorg. Chem. Acta 508, 119566.

66 Goud M.C., Joseph G. (2006) Drilling fluid additives and engineering to improve formation integrity, in: $S P E / I A D C$ Indian Drilling Technology Conference and Exhibition, Society of Petroleum Engineers.

67 Zhang L., Lei Q., Luo J., Zeng M., Wang L., Huang D., Wang X., Mannan S., Peng B., Cheng Z. (2019) Natural halloysites-based janus platelet surfactants for the formation of pickering emulsion and enhanced oil recovery, Sci. Rep. $\mathbf{9}$, 1, 1-8.

68 Chevalier Y., Bolzinger M.-A. (2013) Emulsions stabilized with solid nanoparticles: Pickering emulsions, Colloids Surf A Physicochem. Eng. Aspects 439, 23-34.

69 Buerschaper R.A. (1944) Thermal and electrical conductivity of graphite and carbon at low temperatures, J. Appl. Phys. 15, 5, 452-454.

70 Mohamadian N., Ghorbani H., Wood D., Hormozi H.K. (2018) Rheological and filtration characteristics of drilling fluids enhanced by nanoparticles with selected additives: an experimental study, Adv. Geo-Energy Res. 2, 3, 228-236.

71 Annis M.R., Smith M.V. (1996) Drilling fluids technology, Revised Edition, Exxon Company, USA. 